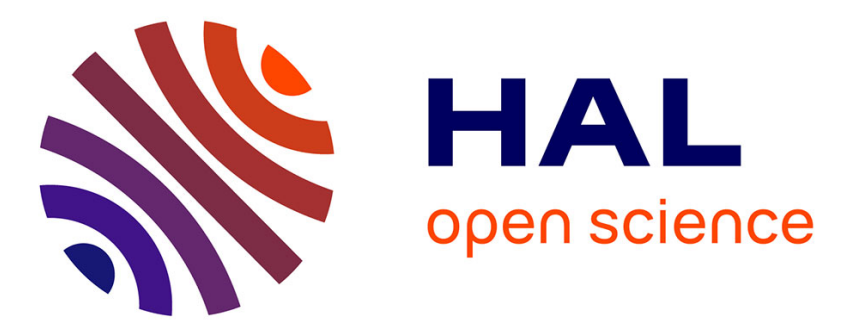

\title{
Efficiency Improvement by the Intermittent Control for Switched Reluctance Machine in Automotive Application
}

Duy-Minh Nguyen, Imen Bahri, Guillaume Krebs, Éric Berthelot, Claude Marchand, Iliya Ralev, Bernhard Burkhart, Rik W. de Doncker

\section{To cite this version:}

Duy-Minh Nguyen, Imen Bahri, Guillaume Krebs, Éric Berthelot, Claude Marchand, et al.. Efficiency Improvement by the Intermittent Control for Switched Reluctance Machine in Automotive Application. IEEE Transactions on Industry Applications, 2019, 55 (4), pp.4167-4182. 10.1109/TIA.2019.2906860 . hal-02505253

\section{HAL Id: hal-02505253}

https://hal-centralesupelec.archives-ouvertes.fr/hal-02505253

Submitted on 11 Mar 2020

HAL is a multi-disciplinary open access archive for the deposit and dissemination of scientific research documents, whether they are published or not. The documents may come from teaching and research institutions in France or abroad, or from public or private research centers.
L'archive ouverte pluridisciplinaire HAL, est destinée au dépôt et à la diffusion de documents scientifiques de niveau recherche, publiés ou non, émanant des établissements d'enseignement et de recherche français ou étrangers, des laboratoires publics ou privés. 


\section{Efficiency Improvement by the Intermittent Control for Switched Reluctance Machine in Automotive Application}

\author{
Duy-Minh Nguyen, Imen Bahri, Guillaume Krebs, Eric \\ Berthelot, Claude Marchand \\ GeePs | Group of electrical engineering Paris, CNRS \\ CentraleSupelec, Univ. Paris-Sud, Univ. Paris-Saclay \\ Univ. Pierre et Marie Curie, Univ. Sorbonne \\ 3, 11 Rue Joliot-Curie 91192 Gif-sur-Yvette CEDEX, France \\ \{duy-minh.nguyen, claude.marchand\}@centralesupelec.fr
}

\author{
Iliya Ralev, Bernhard Burkhart, Rik W. De Doncker \\ ISEA | Institute for Power Electronics and Electrical Drives \\ RWTH Aachen University \\ Jaegerstr. 17-19 52066 Aachen, Germany \\ fi@isea.rwth-aachen.de
}

\begin{abstract}
In this paper, the intermittent control is proposed for switched reluctance machine drive to both increase the efficiency and decrease the cost of the traction system for low-cost electric vehicles. With the purpose of maintaining the average machine torque required by the load, the intermittent control imposes a higher phase torque during a shorter time. The simulation and experimental results achieved with three different switched reluctance machines show that the intermittent control increases the system efficiency by reducing the converter losses and the core losses. Additionally, three different strategies of the control have been proposed to analyze their impact automotive application based on the criteria of efficiency, machine vibration and torque pulsation. It can also be easily applied for any switched reluctance machines using average-torque-controlbased methods.

Index Terms--Average torque, electric vehicle, system efficiency, intermittent control, losses, sliding control, switched reluctance machine drive.
\end{abstract}

\section{INTRODUCTION}

Switched reluctance machine (SRM) is a valuable choice as traction machine for electric vehicles thanks to its advantages. Specifically, the SRM has low cost thanks to the permanent magnet suppression, robust structure and high temperature performance thanks to the simple rotor structure [1]. The intended application of this work is the electric motorization of low-cost electric vehicles. It is therefore with great discernment that car manufacturers are interested in the SRM. For this type of vehicle, it is obviously the autonomy that is considered in priority, while the maximum driving pleasure in terms of comfort in particular should be preserved. On the one hand, many researches focus on the design of the SRM to improve the efficiency [2-7]. On the other hand, many control methods are proposed to improve the efficiency and to reduce the losses. Two solution groups are found based on average torque control (ATC) and instantaneous torque control (ITC).

In the first group, the solutions develop the ATC to achieve better efficiency while profit wide range operation of the ATC. [8-11] propose a controller that determines the turn-on angle and the conduction angle of the ATC to maximize the efficiency over the entire speed range. The optimization of the set of current control parameters of the ATC is the subject of
[12-13] in the purpose of achieving different criteria such as maximization of efficiency, minimization of vibration and torque ripple. [14] proposes three magnetization modes with the ATC in which the magnetization region is shifted according to load based on a linear torque equation to maximize the efficiency. [15] presents three novel methods to optimize the ATC: current chopping control, angle position control and hybrid crossover control which optimize turn-on and turn-off angles of the SRM by generic algorithm to enhance driving efficiency and reduce torque ripple. [16] investigates new current profile which is represented as a Fourier sum of three harmonics, and the phase shift of these harmonics. It leads to optimized solutions of the ATC that simultaneously minimize acoustic noise, vibration, and qualities such as copper loss, peak current, or torque ripple. [17] examines an optimization method for the zero-volt loop in the ATC to minimize losses at all speed and partial load, especially at medium speed and partial load.

In the second group, the solutions [18-22] tend to improve the efficiency aspect of the ITC which is applied for the constant torque region to mainly minimize the torque ripple and produce smooth torque. In [23], impact of smooth torque control on the efficiency of an SR drive is discussed. The priority of smooth torque often leads to a trade-off with the efficiency and the proposed methods tend to reduce such compromise. The ATC seems to be the method that permits to realize different optimization criteria, including the maximization of efficiency, on the entire operating zone. Recent overview on different control methods of the SRM can be found in [24].

In general, electrical machines in electric vehicles are operated mainly in the medium-low torque zone of the torquespeed plane in both motor mode (green, positive torque) and generator mode (red, negative torque) as shown in Fig. 1. In that context, the innovative intermittent control (INC) for the SRM is recently patented in [25] and presented in [26] to respond to the high efficiency demand of low-cost electric vehicles, especially in the medium-low torque zone of the torque-speed plane. This paper presents the INC and experimental validations on several SRMs. 


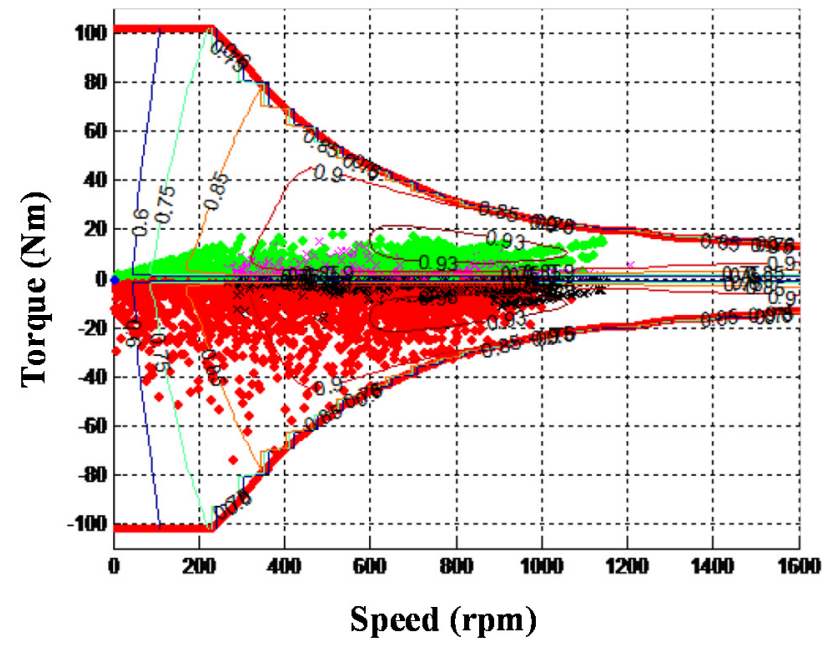

Fig. 1. INRETS driving cycle distribution on electrical machines [27]

Section II describes the considered SRM systems as well as the employed loss model. Section III deduces the principle of the INC from the system efficiency map given by the ATC. The realization and the strategies of the INC are also given in detail. Section IV validates the INC in simulation while section $\mathrm{V}$ validates the control in experimentation with different SRMs. Section VI discusses the impacts of the control on the machine vibration and the vehicle jerks. Section VII comments on the results.

\section{SYSTEM DESCRIPTION}

\section{A. SRM System}

The Tab. IX presents the used SRMs. The first SRM is an 8/6 four-phase machine (SRM M1) which permits to quickly develop and test the control strategies and is used in sections III, IV, V and VI. The second SRM is an 18/12 three-phase machine (SRM M2) which is designed for automotive application and is used for experimental validation in section V. The third SRM is an 8/6 four-phase machine (SRM M3) is used to discuss the vehicle jerks in section VI.

The SRM M1 is modeled by flux linkage and electromagnetic torque tables in function of phase current and rotor position [28] with data extracted from a laboratory software based on finite element analysis called "MRVSIM" [29]. As coupling between the phases of the SRM is weak, it is assumed that each phase current produces an independent phase torque [28]. The power converter consists of asymmetrical half-bridge stages with two MOSFETs and two diodes per stage.

\section{B. Loss Calculation}

The losses of the SRM system comprises the converter losses and the machine losses [23]. The converter losses are mainly caused by the semi-conductors from their two status of conduction and commutation (switching). The conduction losses are mainly due to the ohmic effect and the voltage drop in the components. The commutation losses are the energies dissipated during the rising time and the falling time.

The machine losses consist of the winding losses and the core losses. The winding losses $P_{\text {winding }}$ are decomposed into DC and AC losses. The AC losses in the SRM, which originate from the eddy current in the conducting material, can be important at high speed if one does not pay particular attention to the realization of the winding [30-31]. In this work, the authors consider that this point has been carefully studied: the number of strands in parallel per wire, as well as the distribution of turns in the slot have been optimized. Therefore, only DC losses, which originate from the ohmic effect, are considered. They are calculated for $q$ phases from the phase resistance $R_{p h}$ and the effective current $I_{r m s}$ at the operating temperature.

$$
P_{\text {winding }}=q \cdot R_{p h} \cdot I_{r m s}^{2}
$$

The core losses $P_{\text {core }}$ are calculated separately for different parts of the stator and are decomposed into losses by hysteresis and by eddy current, based on the classic Steinmetz equations [32], with core volume $V$, electrical frequency $f_{\text {elec }}$, flux density $B$, and coefficients $K_{H}, K_{E}$.

$$
P_{\text {core }}=V \cdot\left(f_{\text {elec }} \cdot K_{H} \cdot(\Delta B)^{2}+K_{E} \cdot(d B / d t)_{r m s}^{2}\right)
$$

The mechanical losses take into account only the aerodynamic losses. These losses are dependent on the rotation speed and do not change by different torque controls. Plus, they are relatively small in the investigated speed range compared to the remaining system losses (at $5000 \mathrm{rpm}$ of the SRM M1, these losses equal $0.4 \mathrm{~W}$, which take $0.22 \%$ of the total losses). Therefore, the mechanical losses are neglected in this paper. The system efficiency is calculated from the mechanical power $P_{\text {mec }}$ and the total loss power of the system $P_{t o t}$ :

$$
\eta=\frac{P_{m e c}}{P_{m e c}+P_{t o t}}
$$

\section{INTERMITTENT CONTROL}

The SRM M1 works with the ATC, from which the INC is developed. The ATC is featured for constant reference current over one conduction period and can be applied for the entire speed range of the SRM [33-34]. The ATC-based control structure comprises a speed loop with an IP speed controller, torque-current lookup tables, and a current loop with a hysteresis current controller (Fig. 2). The hysteresis current controller is chosen for its simplicity. The conduction pulse generator generates the conduction pulses $P$ of the phases from the rotor position and the control angles.

At a given speed $\Omega$, the speed controller generates the reference machine torque $T_{m a}{ }^{*}$. The torque is indirectly controlled through the current loop. The torque-current lookup tables search for the reference current wave, which is characterized by a set of three current control parameters called a triplet: current amplitude $I_{\text {ref }}$, turn-on angle $\psi$ and conduction angle $\theta_{p}$ (Fig. 3). The current controller generates the 


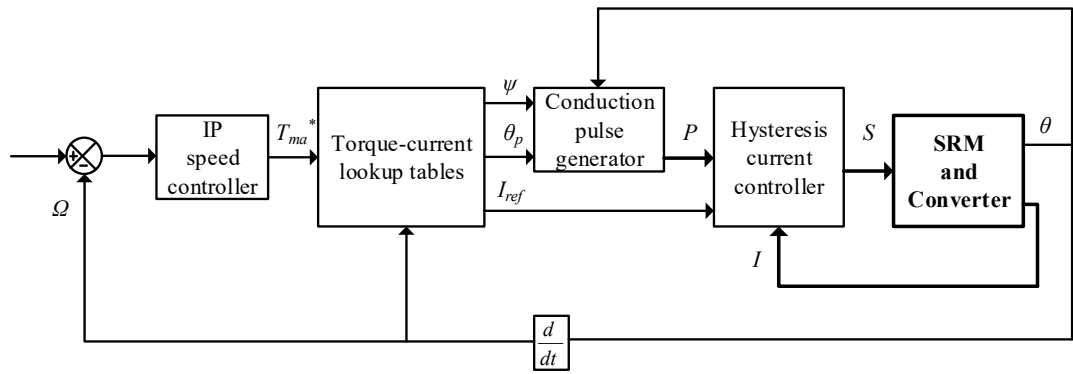

Fig. 2. Control structure of the ATC

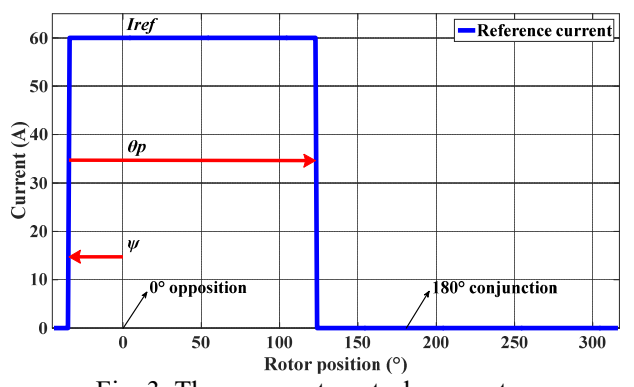

Fig. 3. Three current control parameters switching signals $S$. The torque-current lookup tables are generated offline for the entire torque-speed plane from an optimal selection. In fact, different current control triplets $\left(I_{\text {ref }}\right.$, $\psi, \theta_{p}$ ) are able to operate the SRM at one specific torque-speed point. However, only one control triplet that satisfies a certain optimization criterion (for example, minimizing the torque ripple, minimizing the machine vibration or maximizing the system efficiency) is selected [11-13]. Since the objective of the INC is to increase the efficiency, the criterion of maximizing the efficiency is chosen in this work.

\section{A. Principle of the INC}

Fig. 4 shows the estimated system efficiency map of the SRM M1 (Annex, Tab. IX) given by the ATC. The system achieves an efficiency up to $77 \%$ in high-speed zone. The black line in Fig. 4 indicates the maximum efficiency curve (MEC). The MEC traces the torques with the highest system efficiency over speed. In other words, delivering these torques makes the SRM system get the highest efficiency over speed.

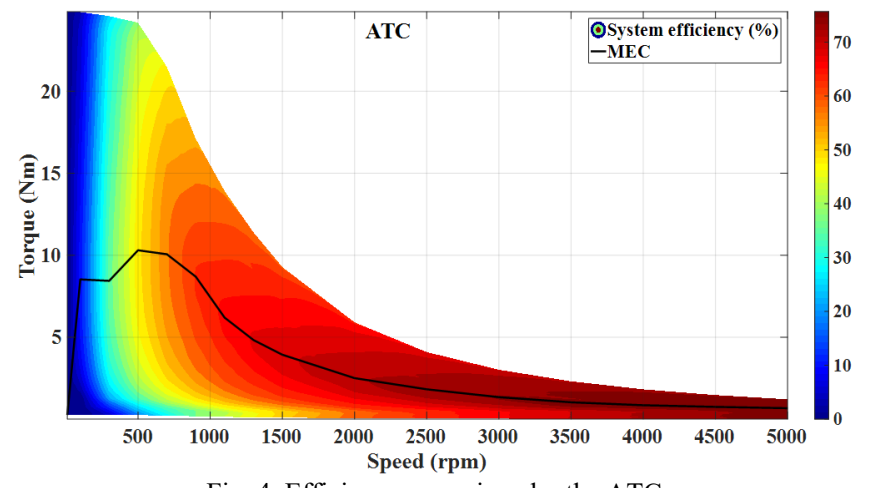

Fig. 4. Efficiency map given by the ATC

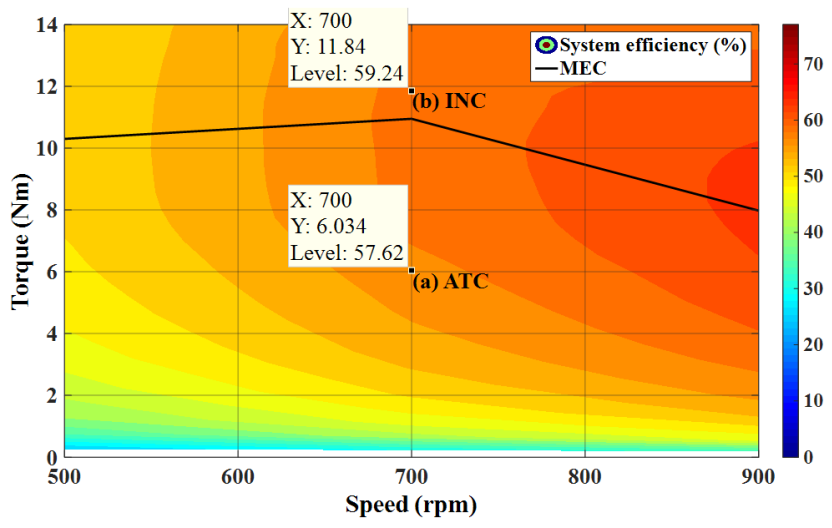

Fig. 5. Reference torques and corresponding efficiencies by the ATC (a) and the INC (b) for the same operating point $700 \mathrm{rpm}, 6 \mathrm{Nm}$

Generally for SRM, the complete excitation is applied to and removed from one phase during each conduction pulse. Hence, each phase independently produces its own torque, and the machine torque is the sum of the phase torques. The idea of the INC is to bring each operating point, whose torque is lower than the MEC, as close as possible to this curve by increasing some phase torques while turning off the other phases during each electrical period to maintain the machine torque.

Fig. 5 shows a zoom of Fig. 4 to explain theoretically the idea of the INC at a specific operating point: $700 \mathrm{rpm}, 6 \mathrm{Nm}$. The ATC (a) delivers four phase torques of $6 \mathrm{Nm}$. The corresponding efficiency is $57.6 \%$. The INC (b) delivers two phase torques of $12 \mathrm{Nm}$. The corresponding efficiency is $59.2 \%$. With both controls, the average machine torque is $6 \mathrm{Nm}$, but the efficiency is increased by 1.6 percentage points (pp). The efficiency gain corresponds to a reduction of losses, or, a reduction of input power by $3.4 \%$. Since certain phases are turned off, this method is called "intermittent control".

Fig. 6 shows the current and torque waveforms of both the ATC and the INC at the same specific operating point: $700 \mathrm{rpm}, 6 \mathrm{Nm}$. The ATC (a) supplies four phases with a current of $32 \mathrm{~A}$ to produce four phase torques with a reference $T_{p h}{ }^{*}=6 \mathrm{Nm}$. The INC (b) supplies phases 1 and 2 with a current of $60 \mathrm{~A}$ to produce two phase torques with a reference $T_{p h}{ }^{*}=12 \mathrm{Nm}$. The currents and the torques of phases 3 and 4 are zero. In both cases, the average machine torque $\bar{T}_{m a}=6 \mathrm{Nm}$. The instantaneous machine torque $T_{m a}$ of the SRM gets discontinuous under the INC and could affect the performance of the machine. With proper sliding strategies applied, a degradation of vibration and torque propulsion can be avoided.

\section{B. Realization of the INC}

The INC is realized from the control structure of the ATC. Involving in the reference torque and the conduction pulse, the INC adds three more blocks to the control structure of the ATC: the $\alpha$-generator, the torque adapter and the pulse adapter as shown in (Fig. 7, red blocks).

a-generator: Since the SRM has four phases, the INC can be realized within four cases: from one phase ON to four phases ON for each operating point. The ratio between the number of supplied phases $k$ and the number of phases $q$ is 
called the duty cycle " $\alpha$ " of the INC:

$$
\alpha=\frac{k}{q}, \text { where } 1 \leq k \leq q .
$$

For each operating point, only duty cycles $\alpha$ that keep the machine working under the torque-speed curve are permitted. Among these permitted $\alpha$, only one $\alpha$ that gives the highest efficiency is selected. Fig. 8 shows the estimated duty cycle map for the entire torque-speed plane. As seen in this map, the duty cycles $\alpha=\{1 / 4,2 / 4,3 / 4,4 / 4\}$ are respectively applied on zone (a), (b), (c) and (d). In zone (d), the ATC already gives the highest efficiency. The INC cannot be applied above the MEC, since the machine torque cannot be maintained when the phase torque is decreased. This $\alpha$ map is pregenerated and stored in a lookup table as $\alpha$ generator.

The torque adapter is a factor that determines the reference phase torque $T_{p h}^{*}$ from the reference machine torque $T_{m a}^{*}$ :

$$
\alpha \cdot T_{p h}^{*}=T_{m a}^{*}, \text { thus } T_{p h}^{*}=\frac{1}{\alpha} \cdot T_{m a}^{*} .
$$

The pulse adapter is an algorithm that generates the INC conduction pulses $p_{i}$ ' from the ATC conduction pulses $p_{i}$ as:

$$
p_{i}^{\prime}=p_{i} \cdot f_{i}, \text { where } f_{i}= \begin{cases}1, & \text { if phase } i \text { is ON } \\ 0, & \text { if phase } i \text { is OFF }\end{cases}
$$

\section{Strategies of the INC}

During each electrical period, the activated phases can be chosen freely. This section presents different phase-selection strategies of the INC which can influence the machine vibration and the torque pulsation of the SRM. In the initial strategy presented in the principle, the supplied phases are fixed in all electrical periods. There are six electrical periods $\left(T_{e}\right)$ in each mechanical period $\left(T_{m}\right)$ (Fig. 9b). The supplied phases can be shifted regularly in the increasing direction (direct sliding, Fig. 9c) or in the decreasing direction (inverse sliding, Fig. 9d).
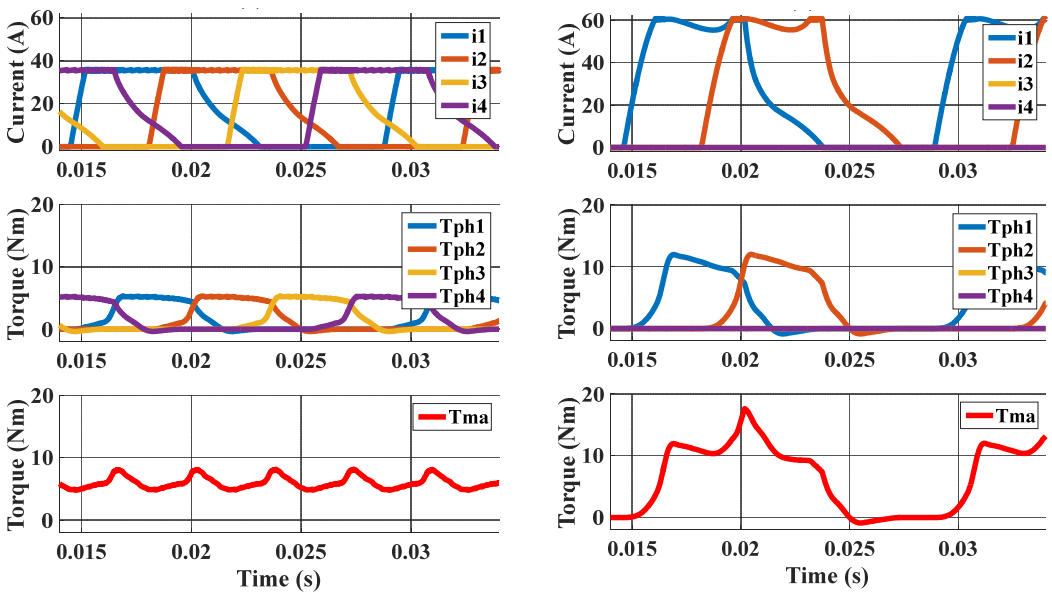

(b) INC

(a) ATC

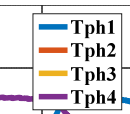

0250.03

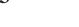

g. 6. Current and torque waveforms of the ATC (a) and the INC (b)

$$
\text { for a resulting } \bar{T}_{m a}=6 \mathrm{Nm} \text { at } 700 \mathrm{rpm}
$$

When the supplied phases are shifted regularly, the angular distance between two torque peaks changes. Hence, the number of torque peaks in each mechanical period changes, and the average torque is not assured anymore. Therefore, the reference torque is compensated by a secondary factor sliding cycle " $\beta$ ", which is the ratio between the angular distance of the fixed INC $D_{\text {fixed }}$ and that of the sliding INC $D_{\text {sliding: }}$

$$
\beta=\frac{D_{\text {fixed }}}{D_{\text {sliding }}}
$$

Equation (5) becomes:

$$
\alpha \cdot \beta \cdot T_{p h}^{*}=T_{e m}^{*}, \text { thus } T_{p h}^{*}=\frac{1}{\alpha} \cdot \frac{1}{\beta} \cdot T_{e m}^{*} .
$$

Fixed INC: the supplied phases, noted $p_{i}$, are fixed in all electrical periods (Fig. 9b). The angular distance is $D_{\text {fixed }}=T_{e}$. There are six torque peaks per mechanical period. The supplied phases are noted in Tab. I.

TABLE I. FIXED INC

\begin{tabular}{ccc}
\hline $\boldsymbol{\alpha}$ & Supplied phase(s) & $\boldsymbol{\beta}$ \\
\hline $\mathbf{1} / \mathbf{4}$ & $\mathrm{p} 1$ & \\
$\mathbf{2} / \mathbf{4}$ & $\mathrm{p} 1, \mathrm{p} 2$ & $\mathbf{1}$ \\
$\mathbf{3} / \mathbf{4}$ & $\mathrm{p} 1, \mathrm{p} 2, \mathrm{p} 3$ & \\
\hline
\end{tabular}

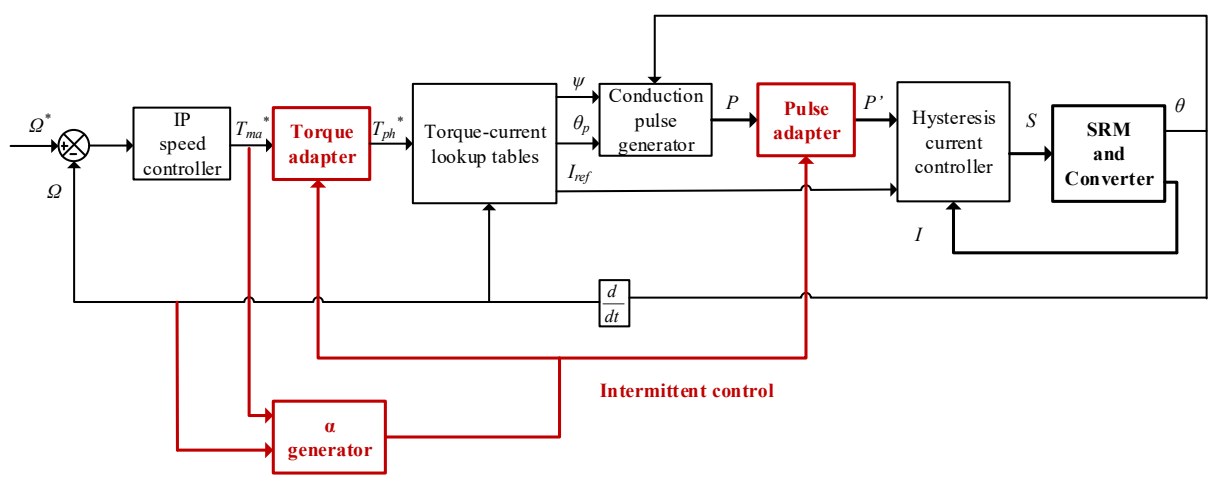

Fig. 7. Control structure of the INC

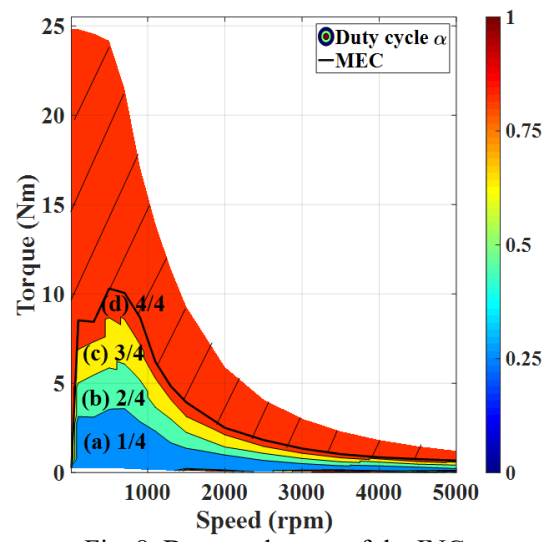

Fig. 8. Duty cycle map of the INC 
Direct sliding INC: the supplied phases are shifted regularly in the increasing direction (Fig. 9c). The angular distance $D_{\text {sliding }}=T_{e}(1+1 / 4)$ is higher than $D_{\text {fixed }}$. There are fewer torque peaks per mechanical period. The generated frequencies of the currents and torques are lower, compared to the fixed INC. The supplied phases are noted in Tab. II.

TABLE II. DIRECT SLIDING INC

\begin{tabular}{cccccc}
\hline \multirow{\alpha}{*}{} & \multicolumn{4}{c}{ Supplied phase(s) } & \multirow{2}{*}{$\boldsymbol{\beta}$} \\
\cline { 2 - 5 } & 1st period & 2nd period & 3rd period & 4th period & \\
\hline $\mathbf{1 / 4}$ & $\mathrm{p} 1$ & $\mathrm{p} 2$ & $\mathrm{p} 3$ & $\mathrm{p} 4$ & \\
$\mathbf{2} / \mathbf{4}$ & $\mathrm{p} 1, \mathrm{p} 2$ & $\mathrm{p} 2, \mathrm{p} 3$ & $\mathrm{p} 3, \mathrm{p} 4$ & $\mathrm{p} 4, \mathrm{p} 1$ & \multirow{4}{*}{$\mathbf{5}$} \\
$\mathbf{3} / \mathbf{4}$ & $\mathrm{p} 1, \mathrm{p} 2, \mathrm{p} 3$ & $\mathrm{p} 2, \mathrm{p} 3, \mathrm{p} 4$ & $\mathrm{p} 3, \mathrm{p} 4, \mathrm{p} 1$ & $\mathrm{p} 4, \mathrm{p} 1, \mathrm{p} 2$ & \\
\hline
\end{tabular}

Inverse sliding INC: the supplied phases are shifted regularly in the decreasing direction (Fig. 9d). The angular distance $D_{\text {sliding }}=T_{e}(1-1 / 4)$ is lower than $D_{\text {fixed }}$. There are more torque peaks per mechanical period. The generated frequencies of the currents and torques are higher, compared to the fixed INC. The supplied phases are noted in Tab. III.

TABLE III. INVERSE SLIDING INC

\begin{tabular}{cccccc}
\hline \multirow{2}{*}{} & \multicolumn{4}{c}{ Supplied phase(s) } & \multirow{2}{*}{$\boldsymbol{\beta}$} \\
\cline { 2 - 5 } & $\mathbf{1}^{\text {st }}$ period & $\mathbf{2}^{\text {nd }}$ period & $\mathbf{3}^{\text {rd }}$ period & $\mathbf{4}^{\text {th }}$ period & \\
\hline $\mathbf{1} / \mathbf{4}$ & $\mathrm{p}_{1}$ & $\mathrm{p}_{4}$ & $\mathrm{p}_{3}$ & $\mathrm{p}_{2}$ & \\
$\mathbf{2} / \mathbf{4}$ & $\mathrm{p}_{1}, \mathrm{p}_{2}$ & $\mathrm{p}_{4}, \mathrm{p}_{1}$ & $\mathrm{p}_{3}, \mathrm{p}_{4}$ & $\mathrm{p}_{2}, \mathrm{p}_{3}$ & $\mathbf{4} / \mathbf{3}$ \\
$\mathbf{3} / \mathbf{4}$ & $\mathrm{p}_{1}, \mathrm{p}_{2}, \mathrm{p}_{3}$ & $\mathrm{p}_{4}, \mathrm{p}_{1}, \mathrm{p}_{2}$ & $\mathrm{p}_{3}, \mathrm{p}_{4}, \mathrm{p}_{1}$ & $\mathrm{p}_{2}, \mathrm{p}_{3}, \mathrm{p}_{4}$ & \\
\hline
\end{tabular}

The strategies of the INC have different impacts on the system efficiency, the machine vibration and the torque pulsation. The machine vibration, which is the origin of the acoustic noise, is discussed in the section VI. The torque pulsation, which is related to the vehicle acceleration, is discussed in the section VII concerning vehicle jerks. Fig. 9 shows examples of the strategies with one phase supplied $(\alpha=1 / 4)$.
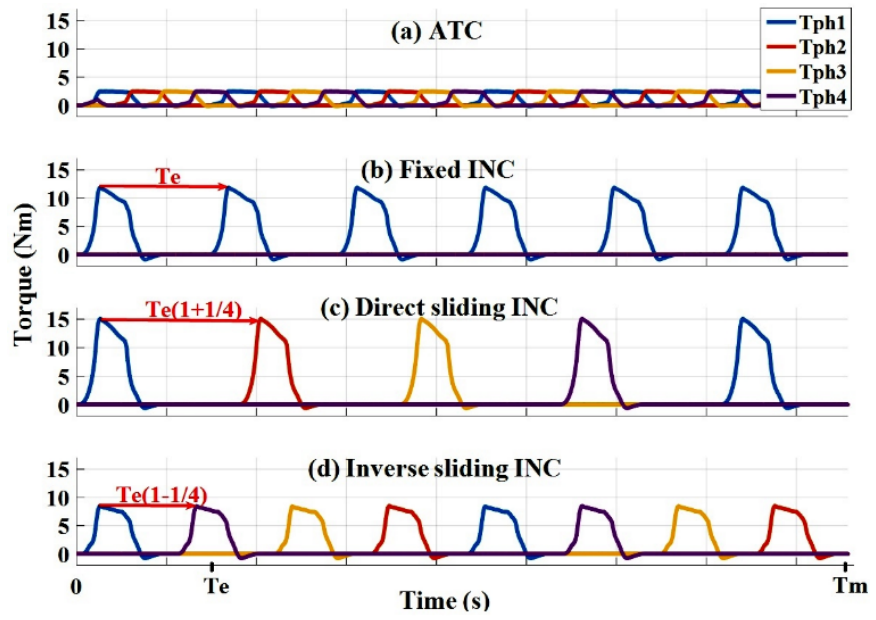

Fig. 9. Torque waveforms of the ATC and the INC strategies during one mechanical period $\mathrm{Tm}$

\section{Simulation VALidATiON}

The impacts of the INC strategies on the system efficiency is evaluated by the following steps: (i) Determination of the system efficiency, the maximum efficiency curve MEC and the duty cycle map with the ATC. (ii) Determination of the average machine torque, the system efficiency and the losses with the INC. (iii) Evaluation of the impact of the INC on different losses. The first step is obtained by the ATC and shown in Fig. 10 as the reference for the comparison.

\section{Fixed INC}

The maximum average torque deviation between the ATC and the fixed INC is shown is Tab. IV. The maximum deviation is $0.06 \mathrm{Nm}$, or $0.85 \%$ of $7.08 \mathrm{Nm}$ at $900 \mathrm{rpm}$. The average torque given by the fixed INC is assured.

Fig. 11a shows the system efficiency difference between the ATC and the fixed INC. The fixed INC increases the efficiency within the applicable zone of the INC. The maximum efficiency gain of $15.50 \mathrm{pp}$ is achieved at $900 \mathrm{rpm}, 0.50 \mathrm{Nm}$. The efficiency gain becomes lower at higher torque.

Fig. 11b shows the total loss difference between the ATC and the fixed INC. The fixed INC decreases the losses for the entire applicable zone of the INC. The maximum reduction of $25.86 \mathrm{~W}$ is achieved at $700 \mathrm{rpm}, 2 \mathrm{Nm}$. In the low torque zone under $5 \mathrm{Nm}$, the loss reduction has an offset of $10 \mathrm{~W}$.

\section{Direct sliding INC}

The average maximum torque deviation between the ATC and the direct sliding INC is shown is Tab. IV. The maximum deviation is $0.07 \mathrm{Nm}$, or $0.99 \%$ of $7.08 \mathrm{Nm}$ at $900 \mathrm{rpm}$. The average torque given by the direct sliding INC is assured.

Fig. 12a shows the system efficiency difference between the ATC and the direct sliding INC. The direct sliding INC partially increases the efficiency for the torque zone under $5 \mathrm{Nm}$ of the applicable zone of the INC. The maximum efficiency gain of $18.12 \mathrm{pp}$ is achieved at $300 \mathrm{rpm}, 0.77 \mathrm{Nm}$.

Fig. 12b shows the total loss difference between the ATC and the direct sliding INC. The direct sliding INC partially decreases the losses for the torque zone under $5 \mathrm{Nm}$ of the applicable zone of the INC. The maximum reduction of $25.66 \mathrm{~W}$ is achieved at $700 \mathrm{rpm}, 1.56 \mathrm{Nm}$. In the low torque zone under $5 \mathrm{Nm}$, the loss reduction has an offset of $8 \mathrm{~W}$.

\section{Inverse sliding INC}

The average maximum torque deviation between the ATC and the inverse sliding INC is shown is Tab. IV. The maximum deviation is $0.05 \mathrm{Nm}$, or $0.96 \%$ of $5.2 \mathrm{Nm}$ at $900 \mathrm{rpm}$. The average torque given by the inverse sliding INC is assured.

Fig. 13a shows the system efficiency difference between the ATC and the inverse sliding INC. The inverse sliding INC partially increases the efficiency for the torque zone under $5 \mathrm{Nm}$ of the applicable zone of the INC. The maximum efficiency gain of $14.08 \mathrm{pp}$ if achieved at $300 \mathrm{rpm}, 0.77 \mathrm{Nm}$.

Fig. 13b shows the total loss difference between the ATC and the inverse sliding INC. The inverse sliding INC partially decreases the losses for the torque zone under $5 \mathrm{Nm}$ of the applicable zone of the INC. The maximum reduction of $23.10 \mathrm{~W}$ if achieved at $700 \mathrm{rpm}, 2 \mathrm{Nm}$. In the low torque zone under $5 \mathrm{Nm}$, the loss reduction has an offset of $10 \mathrm{~W}$. 


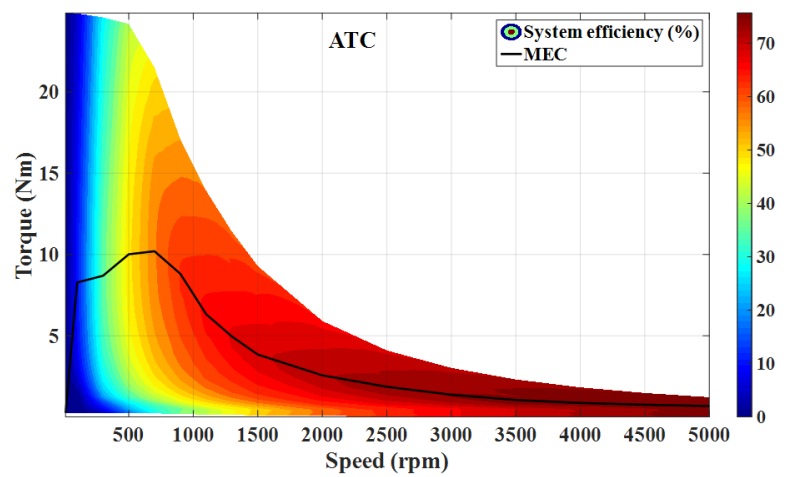

(a) System efficiency

Fig. 10. Performance of the ATC: system efficiency (a) and total loss (b)

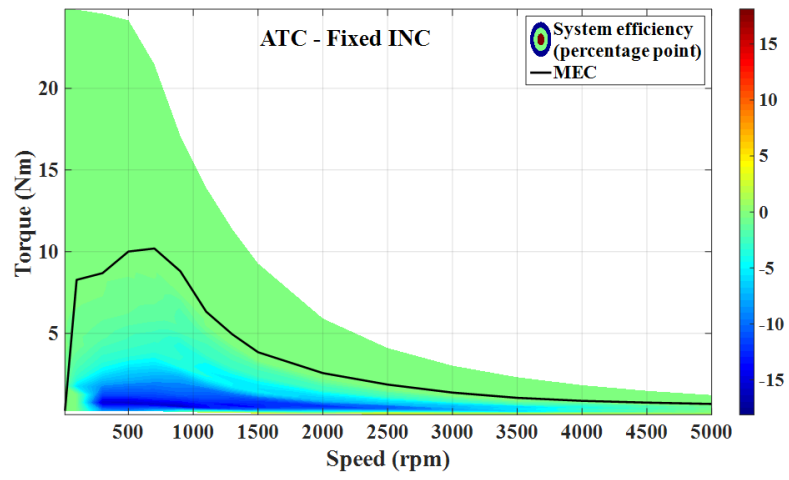

(a) System efficiency

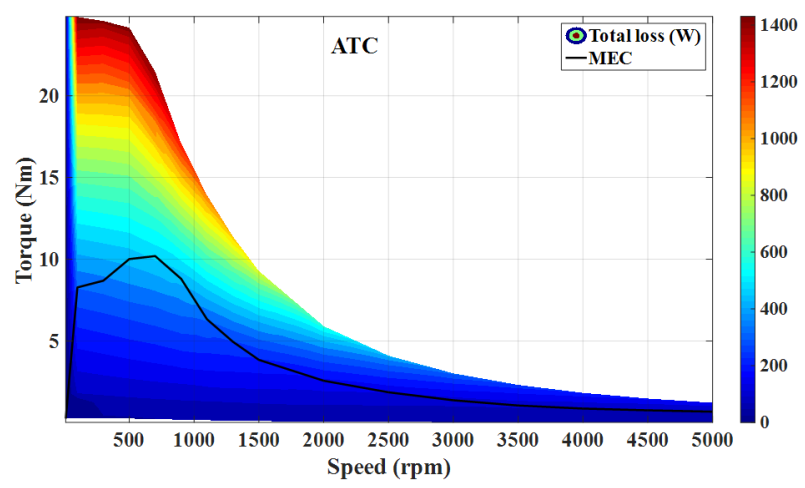

(b) Total loss

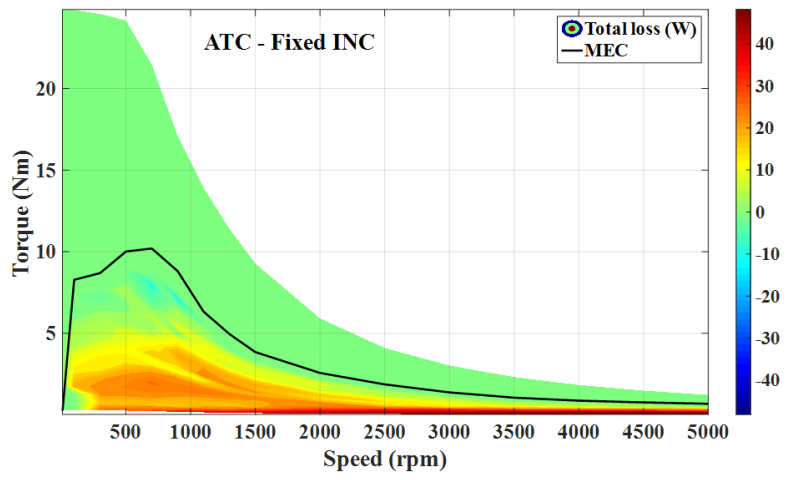

(b) Total loss

Fig. 11. Performance of the fixed INC compared to the ATC: system efficiency (a) and total loss (b)

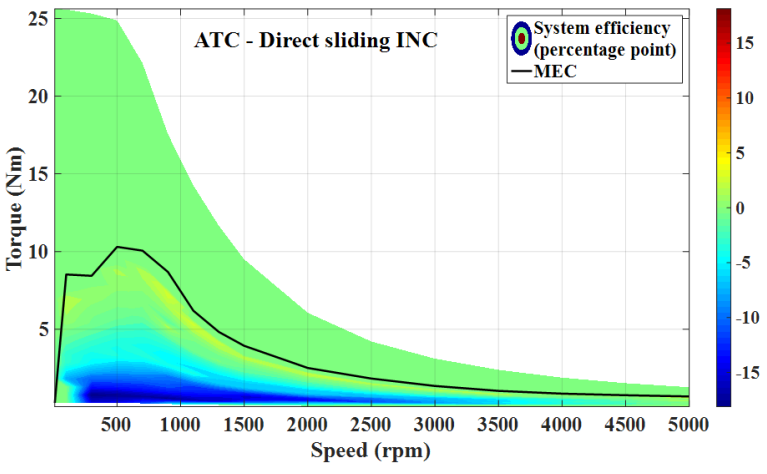

(a) System efficiency

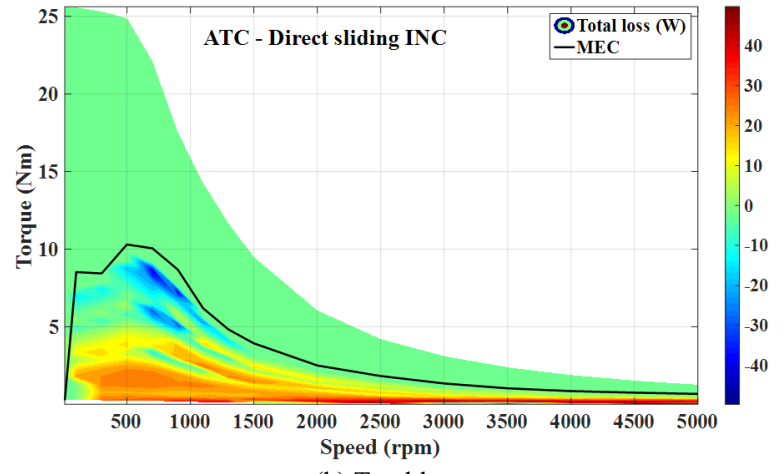

(b) Total loss

Fig. 12. Performance of the direct sliding INC compared to the ATC: system efficiency (a) and total loss (b)

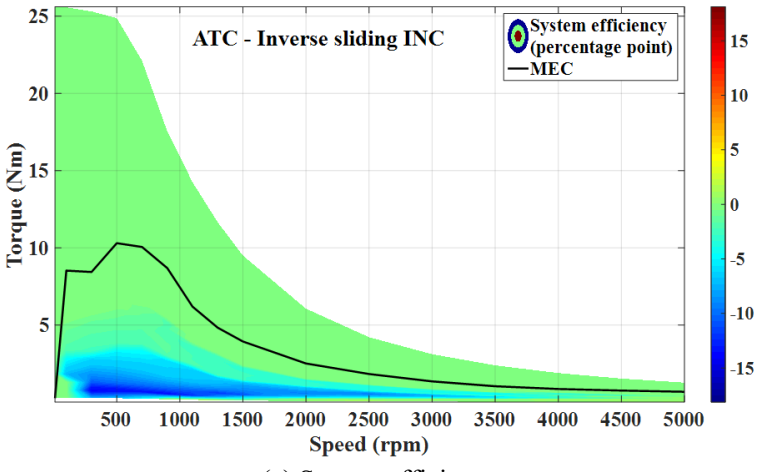

(a) System efficiency

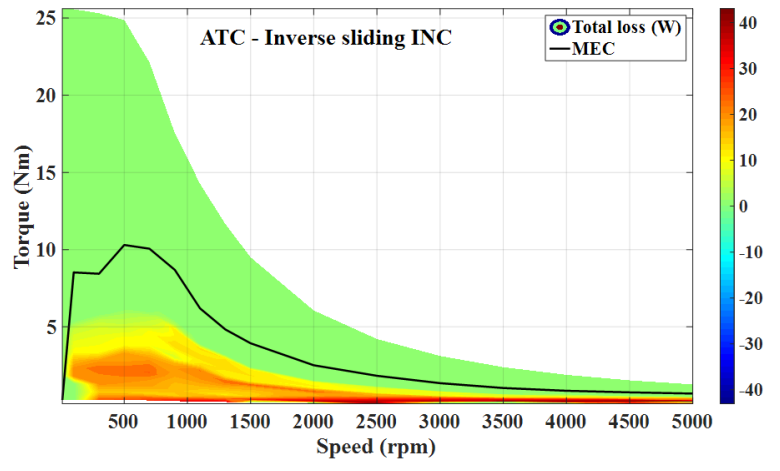

(b) Total loss

Fig. 13. Performance of the inverse sliding INC compared to the ATC: system efficiency (a) and total loss (b) 
TABLE IV. MAXIMUM TORQUE DEVIATION $\mid$ ATC - INC $\mid$

\begin{tabular}{cccc}
\hline & $\begin{array}{c}\text { Fixed } \\
\text { INC }\end{array}$ & $\begin{array}{c}\text { Direct } \\
\text { sliding } \\
\text { INC }\end{array}$ & $\begin{array}{c}\text { Inverse } \\
\text { Sliding } \\
\text { INC }\end{array}$ \\
\hline Operating point & $900 \mathrm{rpm}$ & $900 \mathrm{rpm}$ & $900 \mathrm{rpm}$ \\
& $7.08 \mathrm{Nm}$ & $7.08 \mathrm{Nm}$ & $5.2 \mathrm{Nm}$ \\
Deviation & $0.06 \mathrm{Nm}$ & $0.07 \mathrm{Nm}$ & $0.05 \mathrm{Nm}$ \\
Percentage & $0.85 \%$ & $0.99 \%$ & $0.96 \%$ \\
\hline
\end{tabular}

\section{Comparison of the strategies of the INC}

Tab. V summarizes the efficiency effect of the strategies of the INC. The fixed strategy give the best energy effect. The effective zone of the direct sliding strategy, where it increases the system efficiency and decreases the total loss, is narrower the fixed strategy (under $5 \mathrm{Nm}$ ). Above $5 \mathrm{Nm}$, it decreases the efficiency and increases the loss. The reason is that the reference torque is increased by $\beta=4 / 5$, so it exceeds the energetically optimal torque. The direct sliding INC is not applied for torque zone above $5 \mathrm{Nm}$. The effective zone of the inverse sliding strategy is also narrower the fixed strategy (under $5 \mathrm{Nm}$ ). The reason is that the reference torque is modified by $\beta=4 / 3$, so it is not energetically optimized anymore. In fact, when $\alpha=3 / 4$ and $\beta=4 / 3$, the inverse sliding INC becomes the ATC. The inverse sliding INC is not applied for the torque area above $5 \mathrm{Nm}$.

TABLE V. SIMULATION EFFICIENCY EFFECT

\begin{tabular}{lccc}
\hline & $\begin{array}{c}\text { Fixed } \\
\text { INC }\end{array}$ & $\begin{array}{c}\text { Direct } \\
\text { sliding } \\
\text { INC }\end{array}$ & $\begin{array}{c}\text { Inverse } \\
\text { Sliding } \\
\text { INC }\end{array}$ \\
\hline Efficiency gain max & $15.50 \mathrm{pp}$ & $18.12 \mathrm{pp}$ & $14.08 \mathrm{pp}$ \\
& $900 \mathrm{rpm}$ & $300 \mathrm{rpm}$ & $300 \mathrm{rpm}$ \\
Operating point & $0.50 \mathrm{Nm}$ & $0.77 \mathrm{Nm}$ & $0.77 \mathrm{Nm}$ \\
\hline Loss reduction max & $25.86 \mathrm{~W}$ & $25.66 \mathrm{~W}$ & $23.10 \mathrm{~W}$ \\
Operating point & $700 \mathrm{rpm}$ & $700 \mathrm{rpm}$ & $700 \mathrm{rpm}$ \\
& $2 \mathrm{Nm}$ & $1.56 \mathrm{Nm}$ & $2 \mathrm{Nm}$ \\
\hline Effective zone & $\leq 10 \mathrm{Nm}$ & $\leq 5 \mathrm{Nm}$ & $\leq 5 \mathrm{Nm}$ \\
Offset & $10 \mathrm{~W}$ & $8 \mathrm{~W}$ & $10 \mathrm{~W}$ \\
\hline
\end{tabular}

\section{Impact of the fixed INC on different losses}

The impact of the fixed INC, which is the most energetic effective strategy, on different losses of the system can be found in [26]. The commutation losses are prominent in the low speed zone under the base speed of $700 \mathrm{rpm}$, where the back EMF force is still low and the phase currents reach the reference current. These losses become important in mediumhigh torque zone above $10 \mathrm{Nm}$, where the phase currents rise. The fixed INC decreases the commutation losses up to $2.5 \mathrm{~W}$ at $700 \mathrm{rpm}, 3 \mathrm{Nm}$.

In the SRM M1, the conduction losses are more prominent than the commutation losses. The conduction losses become important in the medium-high torque zone above $10 \mathrm{Nm}$ where the phase currents rise. The fixed INC decreases the conduction losses within the whole applicable zone of the INC.
The maximum reduction is $25 \mathrm{~W}$ at $500 \mathrm{rpm}, 3 \mathrm{Nm}$.

The core losses increase with the rise of the torque and speed, so they are important in the high power zone: from $500 \mathrm{rpm}$ to $2000 \mathrm{rpm}$ and from $5 \mathrm{Nm}$ to $25 \mathrm{Nm}$. The fixed INC decreases the core losses within the whole applicable zone of the INC. The maximum reduction is $9 \mathrm{~W}$ at $700 \mathrm{rpm}, 3 \mathrm{Nm}$.

The winding DC losses are the most important losses in the SRM. These losses are most prominent in the high power zone above $20 \mathrm{Nm}$, where the phase currents are high. The winding losses are increased because the fixed INC increases the phase torques and hence the phase currents. However, the phase currents are not proportional to the phase torques because the reference current is optimized with three parameters. So, the increase of the winding losses is not linearly proportional. In general, the total loss is decreased as already shown in Fig. 11b.

Tab. VI shows an example at $900 \mathrm{rpm}, 4 \mathrm{Nm}$ with the total loss reduction of $17.7 \mathrm{~W}$. The reductions of the commutation, conduction and core losses are $2.5 \mathrm{~W}, 18.5 \mathrm{~W}$ and $7.9 \mathrm{~W}$ respectively. The increase of the winding losses is $11.2 \mathrm{~W}$. The core and the conduction losses are the two main loss components that are reduced by the fixed INC.

TABLE VI. LOSS EVOLUTION EXAMPLE

\begin{tabular}{lcc}
\hline Loss $(\mathbf{W})$ & Evolution & Impact \\
\hline Commutation losses & 2.5 & Reduction \\
Conduction losses & 18.5 & Reduction \\
Core losses & 7.9 & Reduction \\
Winding losses & -11.2 & Increase \\
\hline Total & $\mathbf{1 7 . 7}$ & Reduction \\
\hline
\end{tabular}

\section{EXPERIMENTAL VALIDATION}

In this section, the INC is experimentally validated on the small SRM M1 and the traction SRM M2. Tests on the SRM $\mathrm{M} 2$ gives an idea on how much power the INC can save for an electric vehicle.

\section{A. SRMMI}

First, the INC is implemented on the SRM M1, which allows fast evaluation and validation of the control. Its test bench is shown in Fig. 14.

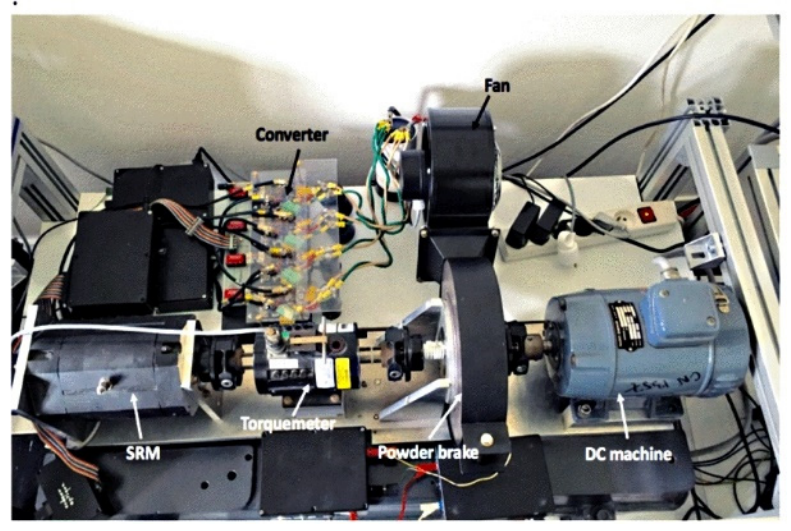

Fig. 14. Test bench of the SRM M1 
The test bench consists of three main elements: the SRM system, the torque-controlled load, the control unit and the measurement devices. The SRM system comprises the converter and the SRM supplied by a DC source and coupled with the torque-controlled load, which permits to adjust the load torque. The control unit is based on a digital control processor dSPACE equipped with an FPGA. In fact, the speed and torque regulation is performed by the processor while the current regulation is performed by the fast FPGA to assure a short computational time. The measurement devices consist of voltage probes, current sensors, an encoder to measure the rotor angular position/speed and a torque sensor to measure the torque on shaft of the SRM. The test range of the SRM M1 is reduced due to mechanical coupling of the test bench: speeds from $200 \mathrm{rpm}$ to $1000 \mathrm{rpm}$ with a step of $200 \mathrm{rpm}$, torques from $2 \mathrm{Nm}$ to $6 \mathrm{Nm}$ with a step of $2 \mathrm{Nm}$. Measurements are affected on these determined operating points. The operating speed is controlled by the speed-controlled SRM while the operating torque is assured by the torque-controlled load. Only the fixed INC is presented.

\section{Fixed INC on the SRM M1}

Fig. 15 shows the energetic performance of the ATC indicated by the system efficiency (a) and total loss (b). The performance of the ATC is taken as the reference for the relative comparisons with the fixed INC.

Fig. 16a shows the system efficiency difference between the ATC and the fixed INC. The fixed INC increases the system

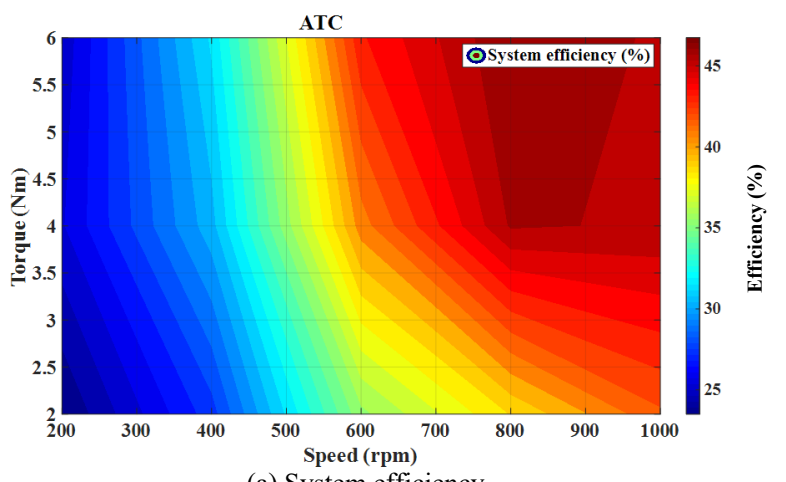

(a) System efficiency

Fig. 15. Performance of the ATC on the SRM M1: system efficiency (a), total loss (b)

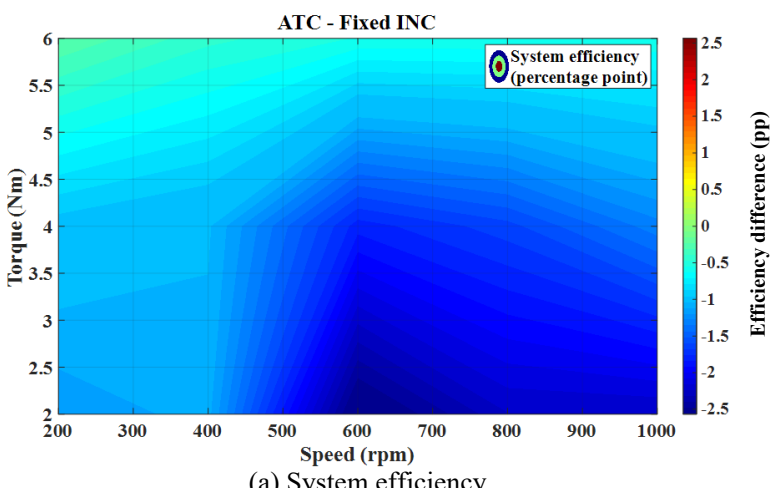

(a) System efficiency efficiency in the test area. The maximum efficiency gain is $2.6 \mathrm{pp}$ and obtained at $600 \mathrm{rpm}, 2 \mathrm{Nm}$. The efficiency gain has an offset of $0.5 \mathrm{pp}$ and becomes lower at higher torque.

Fig. 16b shows the total loss difference between the ATC and the fixed INC. The fixed INC decreases the total loss in the test zone. The maximum reduction is $24.87 \mathrm{~W}$ and is obtained at $600 \mathrm{rpm}, 4 \mathrm{Nm}$. The reduction has an offset of $6 \mathrm{~W}$ in the test zone.

Compared with the simulation in Fig. 11, the experimental performance of the fixed INC has the same tendency, but the experimental efficiency gain and the loss reduction are lower than the simulated ones. This is due to the neglected losses and the rise of the winding DC losses with the rise of the temperature. These experimental results confirm the effectiveness of the INC seen in the simulation (Tab. VII).

TABLE VII. EXPERIMENTAL EFFICIENCY EFFECT WITH M1

\begin{tabular}{lc}
\hline & Fixed INC \\
\hline Efficiency gain max & $2.6 \mathrm{pp}$ \\
Operating point & $600 \mathrm{rpm}, 2 \mathrm{Nm}$ \\
\hline Loss reduction max & $24.78 \mathrm{~W}$ \\
Operating point & $600 \mathrm{rpm}, 4 \mathrm{Nm}$ \\
\hline
\end{tabular}

\section{B. SRMM2}

The effectiveness of the INC is also verified on the traction SRM M2 [23]. The SRM M2 is optimized for acoustic noise aspect and has a different configuration compared to the SRM M1. The specifications of the SRM M2 are given in Tab. IX (Annex). The structure of the test bench of the SRM M2 (Fig. 17) is similar to the SRM M1 test bench. The SRM M2

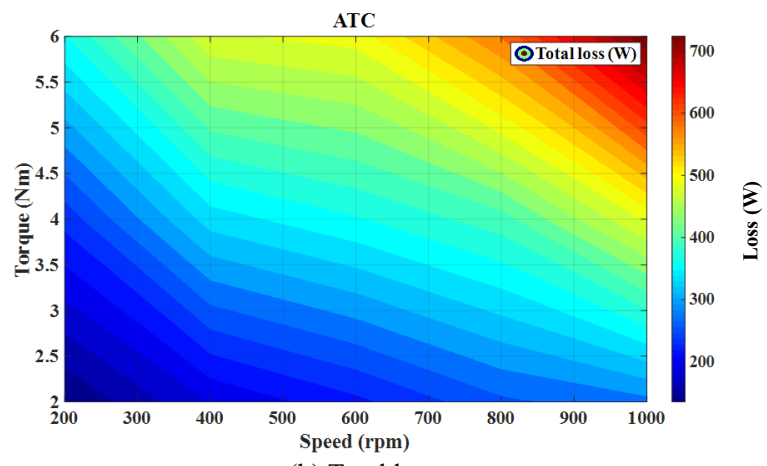

(b) Total loss

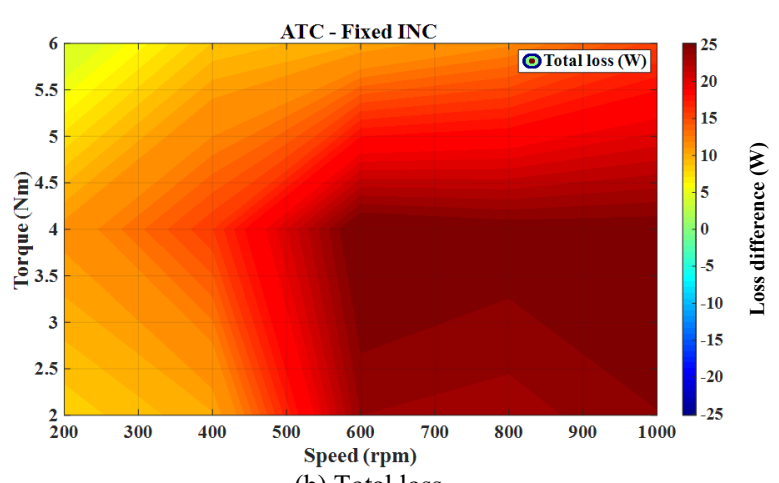

(b) Total loss

Fig. 16. Performance of the fixed INC compared to the ATC on the SRM M1: system efficiency (a), total loss (b) 
is also controlled by the ATC. In this case, the current controller is a variable-width hysteresis. The current waveform is defined by four current control parameters which are the current amplitude, the turn-on angle, the free-wheeling angle and the turn-off angle. The purpose is to reduce the commutations, hence reduce the commutation losses [17].

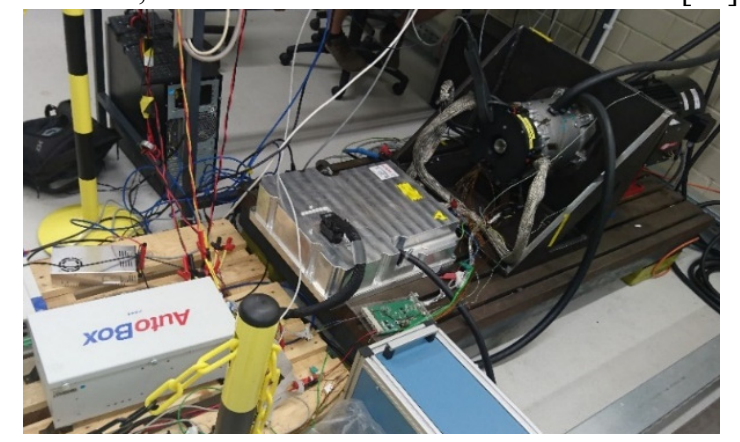

Fig. 17. Test bench of the SRM M2

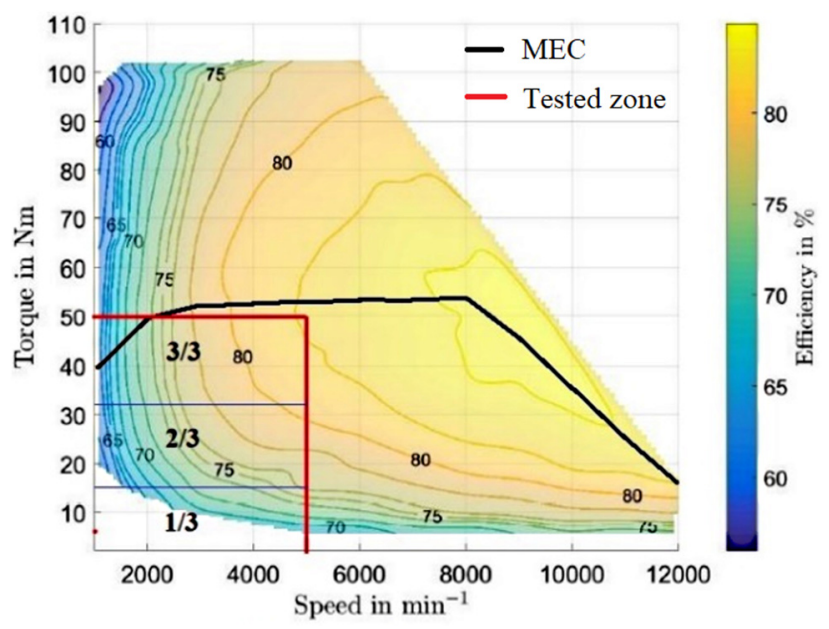

Fig. 18. Efficiency map of the SRM M2 [23]

The INC is also implemented based on the procedure stated in section III. The efficiency map given by the ATC is shown
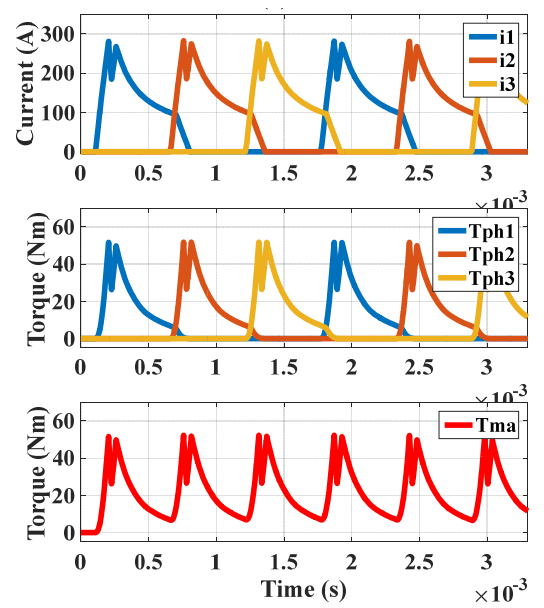

(a) ATC
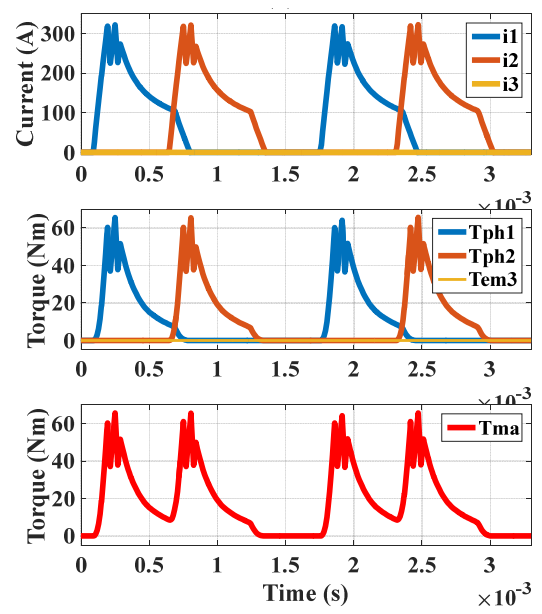

(b) Fixed INC
Fig. 19. Current and torque waveforms of the ATC (a) and the fixed INC (b) for a resulting $\bar{T}_{m a}=20 \mathrm{Nm}$ at $3000 \mathrm{rpm}$ in Fig. 18 [23]. On this map, the MEC is plotted. The applicable zone of the INC on the SRM M2 covers an operating zone up to $50 \mathrm{Nm}$. The applicable zone is then divided into three zones corresponding to three duty cycles $\alpha=\{1 / 3,2 / 3,3 / 3\}$. However, the test zone is limited by the red frame due to mechanical coupling and the cooling effort: speeds from $1000 \mathrm{rpm}$ to $5000 \mathrm{rpm}$ with a step of $1000 \mathrm{rpm}$, torques from $10 \mathrm{Nm}$ to $50 \mathrm{Nm}$ with a step of $5 \mathrm{Nm}$. Only the fixed INC is implemented on this test bench. Fig. 19 shows the current and torque waveforms of the SRM M2 at operating point $3000 \mathrm{rpm}, 20 \mathrm{Nm}$ during two electrical periods. The ATC supplies three phases with the reference phase torque $T_{p h}{ }^{*}=20 \mathrm{Nm}$. The INC supplies only phases 1 and 2 with the reference phase torque $T_{p h}{ }^{*}=30 \mathrm{Nm}$. The average machine torque is $\bar{T}_{m a}=20 \mathrm{Nm}$ in both cases. Fig. 20 shows the energetic performance of the ATC indicated by the system efficiency (a) and total loss (b) as references.

\section{Fixed INC on the SRM M2}

Fig. 21a shows the system efficiency difference between the ATC and the fixed INC. The fixed INC increases the system efficiency in the test zone. The maximum efficiency gain is $6 \mathrm{pp}$ and obtained at $5000 \mathrm{rpm}, 15 \mathrm{Nm}$. The efficiency gain has an offset of $0.5 \mathrm{pp}$ and becomes lower at higher torque.

Fig. 21b shows the total loss difference between the ATC and the fixed INC. The fixed INC decreases the total loss in the test zone. The maximum reduction is $0.8 \mathrm{~kW}$ and obtained at $5000 \mathrm{rpm}, 15 \mathrm{Nm}$. The reduction has an offset of $80 \mathrm{~W}$ in the test zone.

From the loss mechanism of the SRM M2 presented in [23], the ratio of core losses over winding losses is higher compared to the M1. In the low torque zone, the core losses are nearly equal to the winding losses. Therefore, the loss reduction is larger with the SRM M2 (Tab. VIII).

\section{TABLE VIII. EXPERIMENTAL EFFICIENCY EFFECT WITH SRM M2}

\begin{tabular}{lc}
\hline & Fixed INC \\
\hline Efficiency gain max & $6 \mathrm{pp}$ \\
Operating point & $5000 \mathrm{rpm}, 15 \mathrm{Nm}$ \\
\hline Loss reduction max & $800 \mathrm{~W}$ \\
Operating point & $5000 \mathrm{rpm}, 15 \mathrm{Nm}$ \\
\hline
\end{tabular}

\section{CONTROL PERFORMANCE REGARDING MACHINE VIBRATION AND VEHICLE JERKS}

\section{A. Machine vibration}

The SRM is known for acoustic noise which is mainly caused by stator vibration due to high electromagnetic radial force. The radial force appears between the stator and the rotor teeth in operation. It is considered as the dominant force that deforms periodically the stator, causing the vibration. The vibration at certain speeds resonates with the natural frequencies of the stator (own modes), causing the noise. The excitation of the own modes 


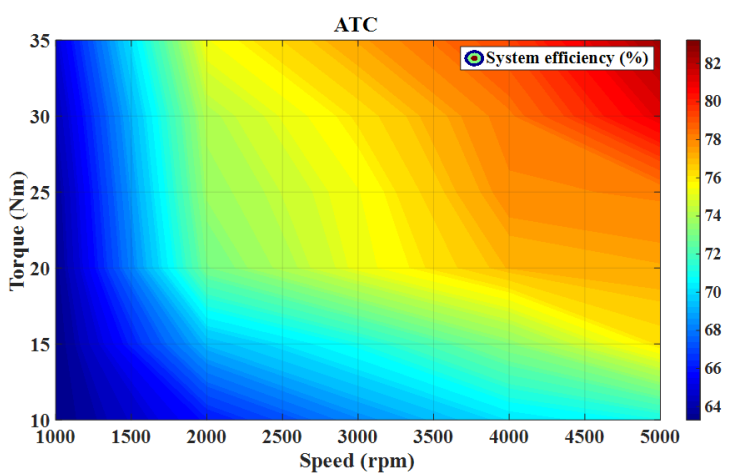

(a) System efficiency

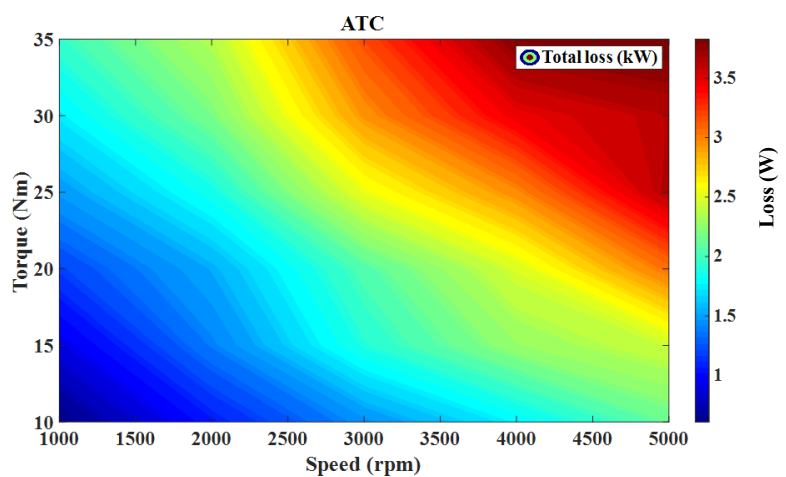

(b) Total loss

Fig. 20. Performance of the ATC on the SRM M2: system efficiency (a), electrical power (b)

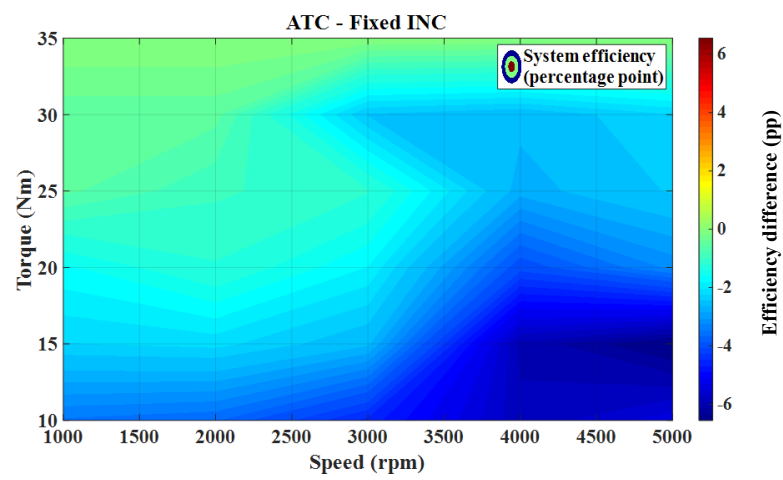

(a) System efficiency

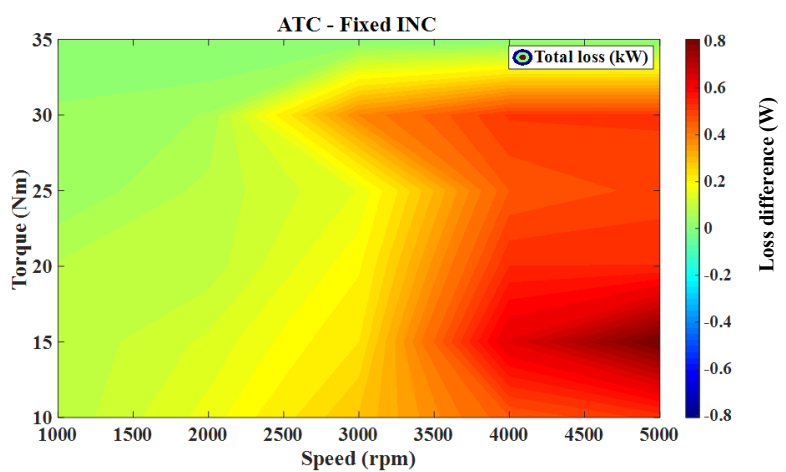

(b) Total loss

Fig. 21. Performance of the fixed INC compared to the ATC on the SRM M2: system efficiency (a), electrical power (b)

depends on both force amplitude and frequencies which are affected by the INC. Therefore, the impact of the INC is discussed.

The own modes of the SRM M1 are obtained here with MRVSIM software: mode $2(2889 \mathrm{~Hz})$, mode $3(7526 \mathrm{~Hz})$, mode $4(12240 \mathrm{~Hz}, 12334 \mathrm{~Hz}, 14136 \mathrm{~Hz})$. With the 4-phase $8 / 6$ SRM, the odd modes are not excited due to symmetrical excitation. A multi-physics electromagnetic mechanical model is used to predict the vibratory behavior of the machine for the mode 2. This mode is the most susceptible to be excited by the controls because it is the closest to the fundamental frequency of the phase current [36].

The direct sliding INC is presented here with the ATC as an example. The Fig. 22 and 23 show the spectrums of the radial forces and accelerations of the mode 2 in simulation as well as the radial accelerations of all the modes in experimentation. The ATC activates four phases. The force spectrums are identical a fundamental frequency of $70 \mathrm{~Hz}$ and an amplitude of $353 \mathrm{~N}$. The acceleration spectrums are identical with a resonance at $2870 \mathrm{~Hz}$. The resonance peak is $2.02 \mathrm{~m} / \mathrm{s}^{2}$ and the resonance (spectral) power is $17.63 \mathrm{~W}$.

The direct sliding strategy activates two phases during each electrical period, but these phases are switched regularly. In consequence, the four phases are excited regularly in an equal way, so that the force spectrums and the acceleration spectrums are identical. Low frequencies appear in the forces, which leads to the rise of the frequencies surrounding the mode
2. In this example, the direct sliding INC reduces the force amplitude by $27.23 \%$. The resonance peaks are reduced by $56.93 \%$. The resonance powers are reduced by $61.09 \%$ despite the rise of the frequencies surrounding the mode 2 . Thus, the machine vibration is reduced.

\section{B. Vehicle jerks}

In an electric vehicle, the torque produced by the electric motor is transmitted to the drive wheels through the drivetrain to create the pulsation. The drivetrain comprises elements as differentials, shafts, axles, gears etc. These elements naturally have a certain elastic level and play a mechanical role in the system. As a result, the drivetrain possesses certain natural frequencies called own modes. These own modes can be excited by the torque, generating the acceleration ripples which are the images of the vehicle jerks. These vehicle jerks can coincide with the natural frequencies of the internal organs of the human body, resulting in unpleasant driving experience.

The INC does not change the average toque but it changes the torque ripples and frequencies, so its impact on the vehicle jerks is discussed with a particular electric vehicle drivetrain. The drivetrain model and analysis can be found in [40]. Fig. 24 shows the bode diagram of the transfer function between the vehicle acceleration $\left(a_{v e h}\right)$ and the machine torque $\left(T_{m a}\right)$. The system presents the own modes: $f_{1}$ at $9 \mathrm{~Hz}, f_{2}$ at $22 \mathrm{~Hz}$ and $f_{3}$ at $70 \mathrm{~Hz}$, which are low frequencies. The resonances at the modes $f_{2}$ and $f_{3}$ tend to be attenuated. 


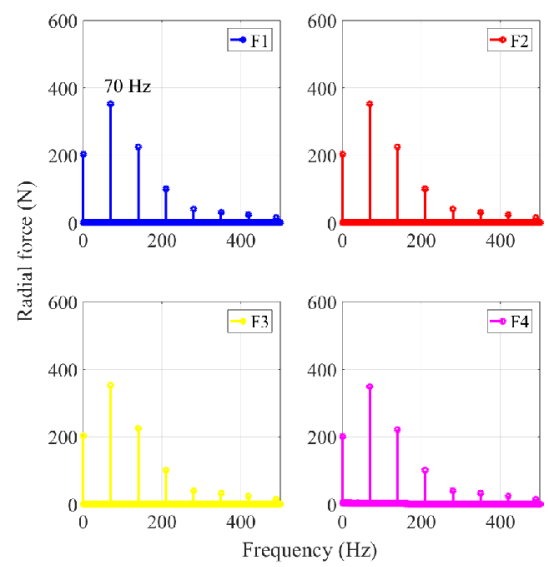

(a) Force spectrums in simulation

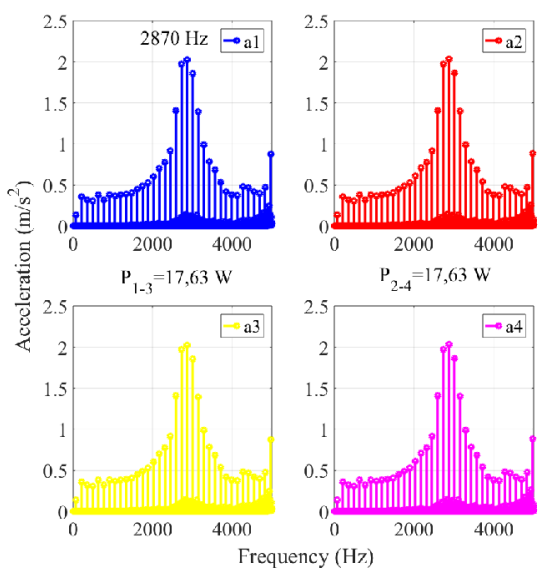

(b) Acceleration spectrums in simulation

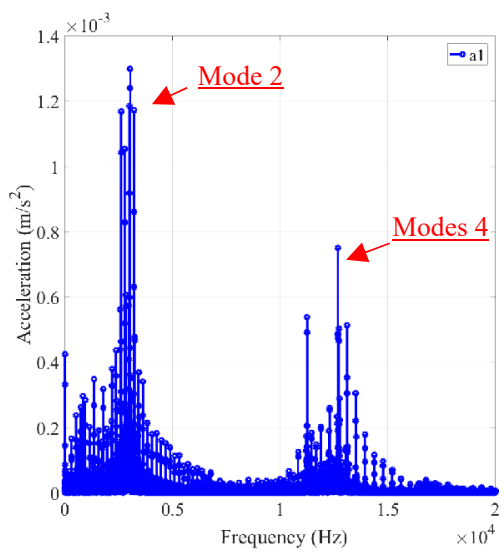

(c) Experimental acceleration

Fig. 22. Radial forces and accelerations by the ATC at $700 \mathrm{rpm}, 4 \mathrm{Nm}$ of the SRM M1

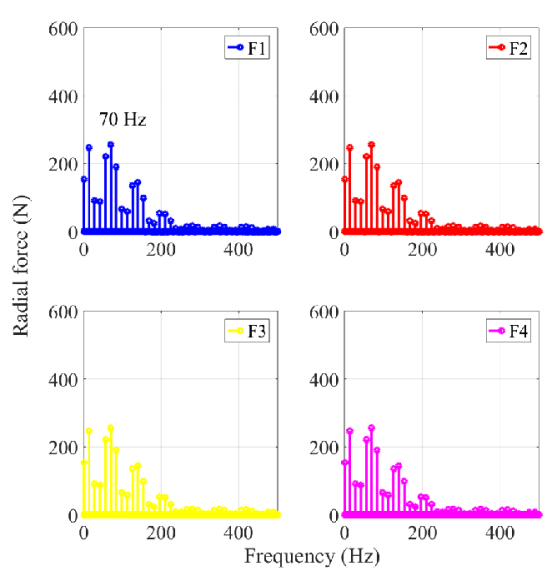

(a) Force spectrums in simulation

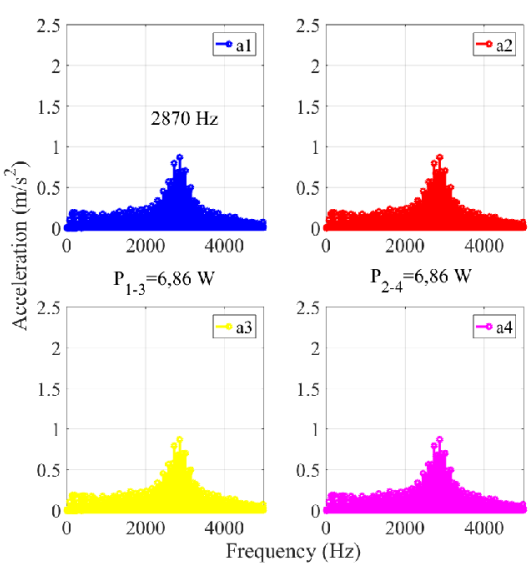

(b) Acceleration spectrums in simulation

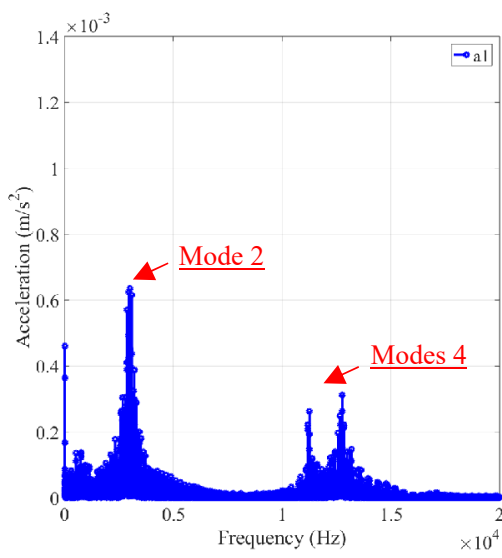

(c) Experimental acceleration

Fig. 23. Radial forces and accelerations by the direct sliding INC at $700 \mathrm{rpm}, 4 \mathrm{Nm}$ of the SRM M1

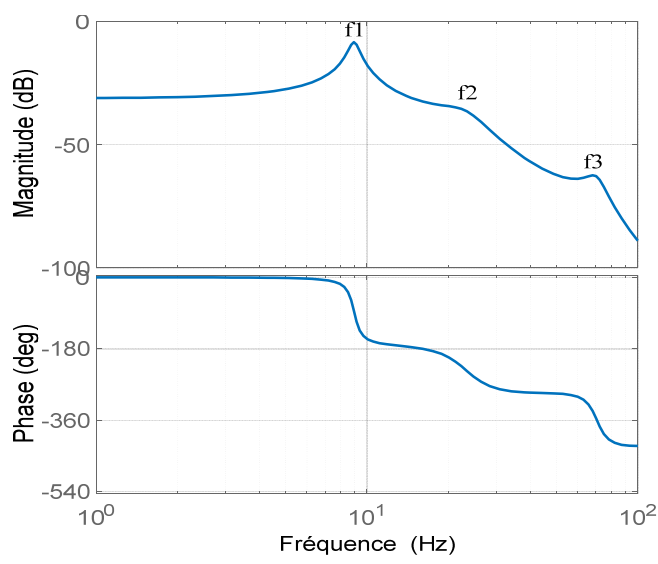

Fig. 24. Bode diagram of the drivetrain

The results in this part are obtained with the SRM M3. The Fig. 25-27 show the machine torque and vehicle acceleration given by the ATC, the fixed INC and the inverse sliding INC at $3850 \mathrm{rpm}, 17 \mathrm{Nm}$ as an example with the SRM M3.
The torque given by the ATC varies between $13 \mathrm{Nm}$ and $26 \mathrm{Nm}$, so the torque ripple is $13 \mathrm{Nm}(76 \%)$. The torque dominant frequency is $1540 \mathrm{~Hz}$. The acceleration is $0.001 \mathrm{~m} / \mathrm{s}^{2}$.

With the fixed INC, the torque ripple is $52 \mathrm{Nm}(306 \%)$. The torque frequencies are lower with the multiples of $385 \mathrm{~Hz}$. The acceleration is increased up to $0.03 \mathrm{~m} / \mathrm{s}^{2}$ with high harmonics.

With the inverse sliding INC, the torque ripple is $36 \mathrm{Nm}$ $(212 \%)$. The torque frequencies are the multiples of $515.5 \mathrm{~Hz}$. However, the acceleration is close to that of the ATC which is under $0.01 \mathrm{~m} / \mathrm{s}^{2}$.

This example show that the torque frequencies play the decisive role in the excitation of the own modes. So, even when the torque ripple is increased, the vehicle acceleration can be kept at a reasonable rate by the inverse sliding strategy.

\section{CONCLUSION}

The INC has been detailed completely with different implementation strategies. The simulation and experiment 


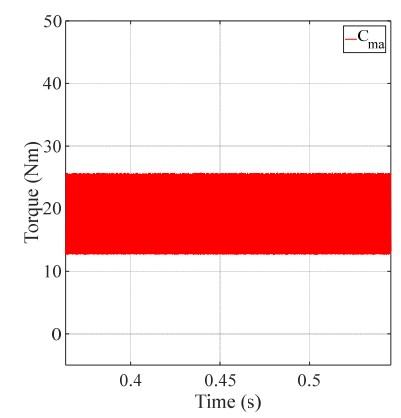

(a) Torque in time

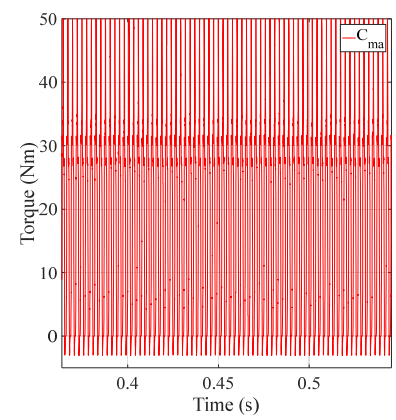

(a) Torque in time

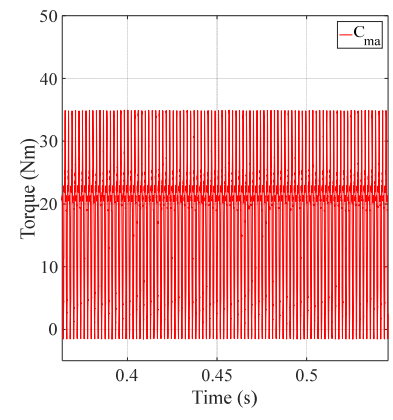

(a) Torque in time

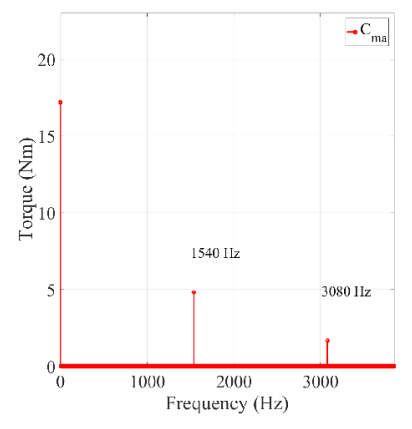

(b) Torque in frequency

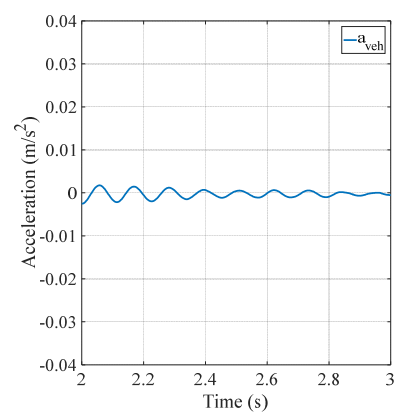

(c) Acceleration in time Fig. 25. ATC

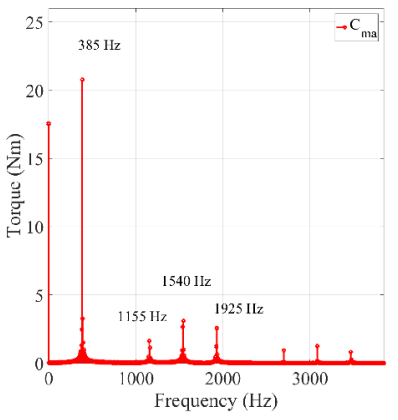

(b) Torque in frequency

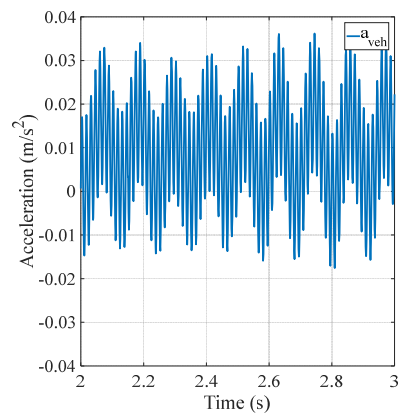

(c) Acceleration in time

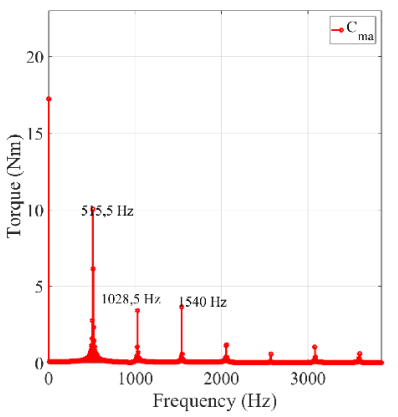

(b) Torque in frequency

Fig. 27. Inverse sliding INC

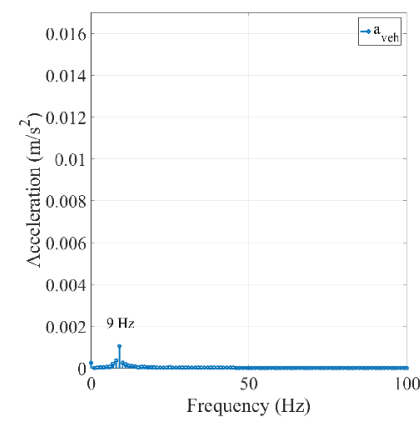

(d) Acceleration in frequency

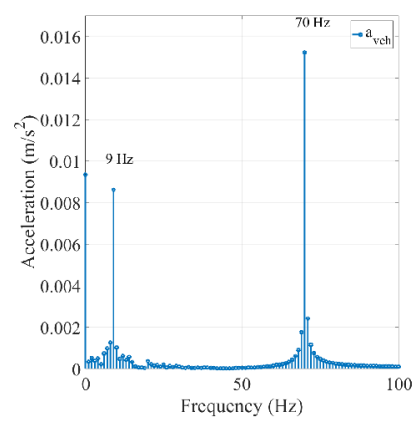

(d) Acceleration in frequency

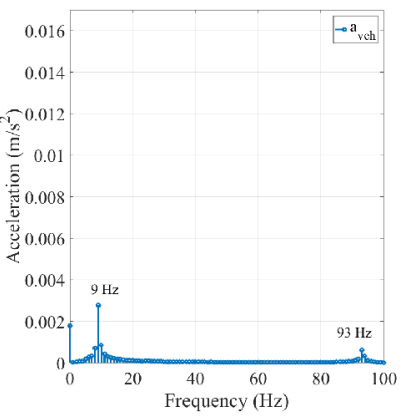

(d) Acceleration in frequency results of the INC have proven that the system efficiency of the SRM is increased while the average torque is maintained within the applicable zone of the MEC. This control mainly reduces the commutation, the conduction and the core losses. The winding DC losses are increased due to the rise of phase currents but the total loss is reduced for the tested SRMs.

The applicable zone of the INC is delimited by the MEC. So, the higher the MEC is, the more applicable the INC is. The position of the MEC in the torque-speed map varies with different SRMs but we can see that the MEC lies on the entire speed range of both SRM M1 and SRM M2. The MEC is quite low in the case of the SRM M1 as this is not a traction machine. However, the MEC goes up to $50 \%$ of the maximal torque in the case of the SRM M2. In brief, the position of the MEC can be a design criterion for the SRM to increase the applicability of the INC.
While the energy criterion is the priority by the fixed strategy, the other criteria related to the drawbacks of the SRM: torque pulsation and machine vibration can be considered to ensure the best possible comfort for the user. For a comparable energy performance, the adoption of sliding strategies can avoid the excitation of the own modes of the stator, the drivetrain, or the mechanical coupling structures. Lastly, the INC should also be verified on standard driving cycles [41].

\section{ACKNOWLEDGMENT}

The traction SRM M2 is an "Optimized electric Drivetrain by INtergration" (ICT FP7 Project 314331, ODIN) funded by the European Union. The results on the SRM M2 in this paper are achieved during a doctoral internship at the institute ISEA. The doctoral internship is sponsored by the laboratory GeePs in the framework of laboratory international mobility program. 
ANNEX

TABLE IX. SRMS DATA

\begin{tabular}{lccc}
\hline & SRM M1 & SRM M2 & SRM M3 \\
\hline Stator poles / Rotor poles & $8 / 6$ & $18 / 12$ & $8 / 6$ \\
Number of phases & 4 & 3 & 4 \\
Bus voltage (V) & 24 & 345 & - \\
Max power (kW) & 2 & 70 & 47 \\
Max torque (Nm) & 25 & 110 & 107 \\
Base speed (rpm) & 700 & 6000 & 7150 \\
Stator diameter (mm) & 140 & 204 & - \\
Active length (mm) & 125 & 120 & - \\
Air gap (mm) & 0.4 & 0.5 & - \\
\hline
\end{tabular}

\section{REFERENCES}

[1] K. M. Rahman, B. Fahimi, G. Suresh, A. V. Rajarathnam and M. Ehsani, "Advantages of switched reluctance motor applications to EV and HEV: design and control issues," in IEEE Transactions on Industry Applications, vol. 36, no. 1, pp. 111-121, Jan/Feb 2000.

[2] K. M. Rahman and S. E. Schulz, "Design of high-efficiency and hightorque-density switched reluctance motor for vehicle propulsion," in IEEE Transactions on Industry Applications, vol. 38, no. 6, pp. 15001507, Nov/Dec 2002.

[3] X. D. Xue, K. W. E. Cheng, T. W. Ng and N. C. Cheung, "MultiObjective Optimization Design of In-Wheel Switched Reluctance Motors in Electric Vehicles," in IEEE Transactions on Industrial Electronics, vol. 57, no. 9, pp. 2980-2987, Sept. 2010.

[4] A. Chiba et al., "Torque Density and Efficiency Improvements of a Switched Reluctance Motor Without Rare-Earth Material for Hybrid Vehicles," in IEEE Transactions on Industry Applications, vol. 47, no. 3, pp. 1240-1246, May-June 2011.

[5] K. Kiyota and A. Chiba, "Design of Switched Reluctance Motor Competitive to $60-\mathrm{kW}$ IPMSM in Third-Generation Hybrid Electric Vehicle," in IEEE Transactions on Industry Applications, vol. 48, no. 6, pp. 2303-2309, Nov.-Dec. 2012.

[6] M. B. Belhadi, A. Kolli, G. Krebs and C. Marchand, "Evaluation of torque-speed curve of switched reluctance motor with segmental rotor," 2012 XXth International Conference on Electrical Machines, Marseille, 2012, pp. 250-255.

[7] M. Belhadi, G. Krebs, C. Marchand, H. Hannoun and X. Mininger, "Evaluation of a switched reluctance motor with magnetic slot wedges," 2014 International Conference on Electrical Machines (ICEM), Berlin, 2014, pp. 150-155.

[8] J. J. Gribble, P. C. Kjaer and T. J. E. Miller, "Optimal commutation in average torque control of switched reluctance motors," in IEE Proceedings - Electric Power Applications, vol. 146, no. 1, pp. 2-10, Jan. 1999.

[9] C. Mademlis and I. Kioskeridis, "Performance optimization in switched reluctance motor systems with online commutation angle control," in IEEE Transactions on Energy Conversion, vol. 18, no. 3, pp. 448-457, Sept. 2003.

[10] I. Kioskeridis and C. Mademlis, "Maximum efficiency in single-pulse controlled switched reluctance motor drives," in IEEE Transactions on Energy Conversion, vol. 20, no. 4, pp. 809-817, Dec. 2005.

[11] M. Rekik, M. Besbes, C. Marchand, B. Multon, S. Loudot, D. Lhotellier, "Optimisation du nombre de spires et des angles de commande d'un moteur à réluctance variable à double saillance pour application de traction électrique", Electrotechnique du Futur, Grenoble, 2005.

[12] E. Bizkevelci, H. B. Ertan and K. Leblebicioglu, "Effects of control parameters on srm performance: A parametric search," 2007 International Aegean Conference on Electrical Machines and Power Electronics, Bodrum, 2007, pp. 276-281

[13] A. Kolli, G. Krebs, X. Mininger and C. Marchand, "Impact of command parameters on efficiency, torque ripple and vibrations for Switched Reluctance motor," 2012 XXth International Conference on Electrical Machines (ICEM), pp. 2975-2980, Marseille, 2012.

[14] Y. Nakazawa, K. Ohyama, H. Fujii, H. Uehara and Y. Hyakutake, "Improvement of efficiency of switched reluctance motor by single pulse control based on linear torque equation," 2013 15th European Conference on Power Electronics and Applications (EPE), Lille, 2013, pp. 1-10.

[15] H. Cheng, H. Chen and Z. Yang, "Average torque control of switched reluctance machine drives for electric vehicles," in IET Electric Power Applications, vol. 9, no. 7, pp. 459-468, 82015.

[16] A. Chiba, "Acoustic noise reduction of switched reluctance motor with reduced RMS current and enhanced efficiency," 2016 IEEE Power and Energy Society General Meeting (PESGM), Boston, MA, 2016, pp. 1-1.

[17] T. Kojima and R. W. De Doncker, "Impact of Zero-Volt Loop Control on Efficiency of Switched Reluctance Motors," in IEEE Transactions on Industry Applications, vol. 53, no. 4, pp. 3621-3634, July-Aug. 2017.

[18] V. P. Vujičić, "Minimization of Torque Ripple and Copper Losses in Switched Reluctance Drive," in IEEE Transactions on Power Electronics, vol. 27, no. 1, pp. 388-399, Jan. 2012.

[19] M. W. Arab, E. Godoy, I. Bahri, M. Hilairet, P. G. Estébanez and S. A. Randi, "Current controller for switched reluctance motors using pole placement approach," 2013 International Electric Machines \& Drives Conference, Chicago, IL, 2013, pp. 1119-1125.

[20] M. W. Arab, X. Rain, M. Hilairet, P. G. Estébanez, H. Hannoun and C. Marchand, "Design of an enhanced adaptive hybrid controller for switched reluctance motors," IECON 2013 - 39th Annual Conference of the IEEE Industrial Electronics Society, Vienna, 2013, pp. 6602-6607.

[21] Y. Wang, H. Wu, W. Zhang and Y. Ma, "A high efficiency direct instantaneous torque control of SRM using commutation angles control," 2014 17th International Conference on Electrical Machines and Systems (ICEMS), Hangzhou, 2014, pp. 2863-2866.

[22] Y. Wang and W. Zhang, "A high efficiency torque control method of switched reluctance motors using low loss commutation control," 2015 18th International Conference on Electrical Machines and Systems (ICEMS), Pattaya, 2015, pp. 2089-2092.

[23] I. Ralev, F. Qi, B. Burkhart, A. Klein-Hessling and R. W. De Doncker, "Impact of Smooth Torque Control on the Efficiency of a High-Speed Automotive Switched Reluctance Drive," in IEEE Transactions on Industry Applications, vol. 53, no. 6, pp. 5509-5517, Nov.-Dec. 2017.

[24] B. Burkhart, A. Klein-Hessling, I. Ralev, C. P. Weiss and R. W. De Doncker, "Technology, research and applications of switched reluctance drives," in CPSS Transactions on Power Electronics and Applications, vol. 2, no. 1, pp. 12-27, 2017.

[25] D. Gilbertas, T. Basbous, "Système et procédé de commande d'une machine électrique équipant un véhicule électrique", Patent: WO2013153304 A1 and EP2836390 A1.

[26] D. M. Nguyen, I. Bahri, G. Krebs and C. Marchand, "Intermittent control for efficiency gain of a switched reluctance machine," 2017 IEEE International Electric Machines and Drives Conference (IEMDC), Miami, FL, 2017, pp. 1-7.

[27] F. Roy, A. M. Catania, F. Ossart and C. Marchand, "Hybrid powertrain design using optimal control strategies," Electric Vehicle Symposium and Exhibition (EVS27), 2013 World, pp. 1-7, Barcelona, 2013.

[28] H. Hannoun, M. Hilairet and C. Marchand, "Analytical modeling of switched reluctance machines including saturation," 2007 IEEE International Electric Machines \& Systems Conference, pp. 564-568, Antalya, 2007.

[29] M. Besbes, B Multon, "MRVSim code: Logiciel de simulation pour l'aide au dimensionnement des MRVDS et de convertisseur", Patent: IDDN.FR.001.430010.000.S.C.2004.000.30645.

[30] M. Al Eit, F. Bouillault, C. Marchand and G. Krebs, "2-D Reduced Model for Eddy Currents Calculation in Litz Wire and Its Application for Switched Reluctance Machine," in IEEE Transactions on Magnetics, vol. 52, no. 3, pp. 1-4, March 2016, Art no. 7401304.

[31] M. Al Eit, P. Dular, F. Bouillault, C. Marchand and G. Krebs, "Perturbation Finite Element Method for Efficient Copper Losses Calculation in Switched Reluctance Machines," in IEEE Transactions on Magnetics, vol. 53, no. 6, pp. 1-4, June 2017, Art no. 7202004.

[32] J. Reinert, A. Brockmeyer and R. W. A. A. De Doncker, "Calculation of losses in ferro- and ferrimagnetic materials based on the modified Stei Nmetz equation," in IEEE Transactions on Industry Applications, vol. 37, no. 4, pp. 1055-1061, Jul/Aug 2001.

[33] H. Hannoun, M. Hilairet and C. Marchand, "Comparison of instantaneous and average torque control for a switched reluctance 
motor," 2008 IEEE International Symposium on Industrial Electronics, pp. 675-680, Cambridge, 2008.

[34] H. Hannoun, M. Hilairet and C. Marchand, "Design of an SRM Speed Control Strategy for a Wide Range of Operating Speeds," in IEEE Transactions on Industrial Electronics, vol. 57, no. 9, pp. 2911-2921, Sept. 2010.

[35] Rasmussen, F. Blaabjerg, J. Pedersen, P. Kjaer, and T. Miller, "Acoustic noise simulation for switched reluctance motors with audible output," in Proc. Eur. Conf. Power Electron. Appl. (EPE), (1999).

[36] J. O. Fiedler, K. A. Kasper and R. W. De Doncker, "Calculation of the Acoustic Noise Spectrum of SRM Using Modal Superposition, " in IEEE Transactions on Industrial Electronics, vol. 57, no. 9, pp. 2939-2945, Sept. 2010.

[37] I. Bahri, H. Maamri, E. Berthelot, E. Godoy and C. Marchand, "Comparison of two control strategies regarding vibration criterion for switched reluctance machine," 8th IET International Conference on Power Electronics, Machines and Drives (PEMD 2016), Glasgow 2016, pp. 1-6.

[38] D. M. Nguyen, I. Bahri, G. Krebs and C. Marchand, "Impact of the intermittent control on the vibration behavior of a switched reluctance machine," 2017 IMACS International conference on theory and application of modeling and simulation in electrical power engineering (Electrimacs), Toulouse, 2017.

[39] Duy-Minh Nguyen, Imen Bahri, Guillaume Krebs, Eric Berthelot, Claude Marchand, "Vibration study of the intermittent control for a switched reluctance machine", Mathematics and Computers in Simulation, 2018, ISSN 0378-4754.

[40] D. M. Nguyen, I. Bahri, G. Krebs and C. Marchand, "Impact of the intermittent control on the torque pulsation of a switched reluctance machine," 2017 IEEE Vehicle Power and Propulsion Conference (VPPC), Belfort, 2017.

[41] D. M. Nguyen, I. Bahri, G. Krebs and C. Marchand, "Performance of the Intermittent Control for Switched Reluctance Machine on Driving Cycle," 2018 International Conference on Electrical Machines (ICEM), Alexandroupoli, 2017. 